\title{
Cuantas más necesidades menos recursos: desigualdades sociales y desequilibrios regionales en la descentralización de servicios sociales
}

\section{Xavier Escandell*}

El modelo de universalización de las prestaciones sociales y servicios sociales que se inicia en 1988 es el resultado de la inversión extraordinaria de recursos en un período protagonizado por el gobierno socialista (1982-1996), una vez consolidada la reforma en los sectores de la educación y la sanidad**. Las políticas socialdemócratas tienen como objetivo explícito el garantizar el crecimiento económico a la vez que garantizar el desarrollo de inversión pública en políticas de protección social, así como un reparto equitativo de los recursos entre las unidades que forman el Estado (Borx; 1996: 26). Los principios que garantizan el reparto de los recursos de forma equitativa entre la población son varios. El principio de suficiencia exige que cada región reciba fondos para realizar atención social proporcional a la población. La descentralización administrativa tiene como consecuencia que la asignación de recursos no siempre se realiza a partir de fórmulas que garanticen los servicios sociales accesibles iguales a toda la población de las Comunidades Autónomas. Existe un cierto descontrol entre la distribución financiera de los recursos totales para servicios sociales en España que genera desequilibrios territoriales, incumpliendo así el principio de equidad entre las Administraciones. Las ineficiencias e irregularidades en el reparto de los recursos se deben a que es difícil garantizar la suficiencia con el principio de autonomía de las regiones. Así pues, los servicios sociales en España muestran desequilibrios, no tanto en su estructura de centros e instalaciones como a nivel de los recursos reales asignados. Se pone así en duda el principio de igualdad en el gasto per capita que garantiza una cantidad similar de recursos para los/as ciudadanos residentes en las Comunidades Autóno- mas que forman el Plan Concertado. Tampoco se mide la relación entre recursos utilizados y los resultados evaluados posteriormente.

\section{Equidad en la descentralización}

La descentralización delega la capacidad de tomar decisiones a las Administraciones más cercanas a la población '. Las Corporaciones Locales se convierten en las instituciones proveedoras y gestoras de servicios sociales básicos. En 1995 los Ayuntamientos, Consejos y Cabildos insulares gestionan ya la cantidad de 36 mil millones de pesetas que representa el $60 \%$ del gasto total en el sector ${ }^{2}$. El proceso de adquisición de competencias administrativas, de gestión y toma de decisiones no se produce al unísono en todas las Comunidades Autónomas. Los servicios sociales se van consolidando a diferentes velocidades en cada Comunidad Autónoma, suponiendo un ejemplo de descentralización interna. Los gobiernos locales y autonómicos están sujetos a los controles constitucionales y administrativos semejantes a los que afectan al gobierno central (Rico, 1996: 47). En ese proceso de descentralización se observan diferencias significativas en las aportaciones de las diferentes Administraciones del Estado, que a su vez puede tener un impacto en la distribución inadecuada de los recursos públicos. 
Un análisis de la red de atención social demuestra que los criterios de reparto del presupuesto global para servicios sociales en términos de equidad territorial no están solucionados. Se incumple una distribución que contemple la asignación de recursos a partir del criterio capitativo simple. Más bien, la distribución de recursos se debe a la capacidad de negociación de cada Comunidad Autónoma con la Administración central respecto a su porcentaje de financiación. No existe una pauta clara para todas las Comunidades Autónomas. La red presenta casos que no se ajustan a la media. Un ejemplo es el caso de la Comunidad Autónoma de Islas Baleares, región que carece de tradición política en la provisión y gestión de servicios públicos para la población desde las Corporaciones Locales, pero que sus Ayuntamientos son los más favorecidos en el presupuesto total anual para servicios sociales (en 1995 el presupuesto total para esa Comunidad es de 1.700 millones de pesetas). El caso opuesto es la Comunidad Autónoma de Cataluña, sus Corporaciones Locáles no alcanzan el 30\% en la aportación del presupuesto anual. La Comunidad históricamente más reivindicativa adopta una negociación entre su Administración autonómica y el Ministerio central, que deja a las Corporaciones Locales en una posición marginal dentro de la red en cuanto a financiación.

En cualquier política distributiva deben ser respetadas la equidad borizontal, vertical $e$ interjurisdiccional. La equidad borizontal hace referencia a que personas en situaciones económicas similares deben recibir un trato similar en la provisión de servicios públicos. La misión del gobierno central (en coordinación con los gobiernos locales) es garantizar y vigilar el cumplimiento de ese principio de equidad horizontal ${ }^{3}$. La equidad vertical supone que personas con niveles de renta distintos deben ser tratados fiscalmente de modo distinto, con énfasis especial en qué nivel jurisdiccional debe definir los criterios de distribución ${ }^{4}$. La equidad jurisdiccional pone en cuestión que las situaciones fiscales de los gobiernos locales entre sí, y respecto al gobierno central, dependen de la capacidad de garantizar la equidad vertical y horizontal. Para alcanzar niveles de equidad interregional se requiere, pues, de trasvases de fondos de las regiones ricas a las regiones más pobres.

El sistema menos transparente para el reparto de recursos públicos es el que se asigna en función de presiones políticas, resultado de negociaciones políticas bilaterales entre las unidades territoriales implicadas y el gobierno central. La distribución de los recursos que se realiza aplicando la fórmula del principio capitativo simple o criterio per capita supone el reparto de financiación según el peso relativo de la población. Otras fórmulas distributivas plantean que los criterios deben seguir los criterios de necesidad en cada región ${ }^{5}$. Ese sistema se considera más eficaz que la negociación política. Las negociaciones políticas se realizan al margen del sistema de representación parla- mentaria y no garantizan suficiente "transparencia" política (RIco, 1996). Los criterios de necesidad tienen que ver con los problemas y necesidades de servicios sociales en cada región que explicarían una inversión mayor en infraestructuras de servicios sociales. Las variables paro, insularidad, y la creación de indices de potenciales usuarios de los servicios, se deben incluir en la fórmula del reparto del Plan Concertado. Algunas de las variables se consideran en los acriterios objetivos de distribución del crédito en Comunidades Autónomas" que marca el Ministerio central. El gobierno central reparte el presupuesto en función de las variables: población, dispersión, grandes urbes, población dependiente, superficie, la insularidad y la pobreza relativa de cada Comunidad ${ }^{6}$. Los criterios objetivos garantizan que cada año se reciba como mínimo el mismo crédito que el año anterior ${ }^{7}$. Pero éstos sólo se aplican a una parte del presupuesto favoreciendo así desigualdades entre las Comunidades más pobres respecto de las más ricas en términos de recursos.

La literatura en economía política sobre la hacienda pública analiza los efectos de la descentralización fiscal en políticas redistributivas en contextos autonómicos y federales. Algunos autores ponen en cuestión que la descentralización sea el mecanismo más adecuado para distribuir los recursos en función de las preferencias y necesidades de la sociedad civil si no se establecen criterios de cooperación entre Administraciones (MusGraves, 1981, OATES, 1972, Ahmad, 1997, Domínguez Del BRío, 1998): El caso español presenta varios problemas que se derivan de un sistema mixto, híbrido, de financiación en que se combina el presupuesto por parte del Ministerio central y la capacidad propia de ingresos de cada Comunidad Autónoma. Este sistema compartido por los países del entorno mediterráneo plantea que el mayor peso del Ministerio central se debe a la resistencia por parte del Estado a abandonar su papel de control-central, que en el caso español está especialmente condicionado por su pasado de dictadura franquista. La dependencia respecto del Ministerio central se debe también a que los gobiernos locales se crean a finales de los setenta, época de fuertes restricciones debido a la crisis económica internacional (BROSIO, 1997: 214).

La asignación de presupuesto para las Comunidades Autónomas por parte del Ministerio depende del signo en el balance del presupuesto que se genera vía los impuestos cedidos a los gobiernos locales. Una financiación mayor del crédito para servicios sociales vía impuestos cedidos a los gobiernos locales y/o autonómicos conlleva subvenciones menores por parte del Estado central. Una mala gestión irregular en la recaudación de impuestos locales se ve compensada por el incremento en las prestaciones que se reciben del Ministerio central. Hay un coste electoral añadido para los gobiernos locales si el crédito asignado depende de la recaudación de impuestos locales. Esos son dos de los efectos perversos del sistema autonómico español de 
financiación. Para el análisis de la equidad territorial es necesario estudiar los criterios que determinan el proceso de asignación de competencias y recursos entre las quince Comunidades Autónomas.

Un efecto negativo del proceso de negociación (los denominados protocolos suscritos entre Comunidades Autónomas y Gobierno central) es que los gobiernos autonómicos, hasta muy avanzada su negociación, no saben cuál va a ser la cantidad de recursos disponibles para cada año. Existe pues un coste de negociación en la planificación de la atención. El proceso es poco transparente y en consecuencia incentiva a los gobiernos locales a ser ineficientes (Brosio, 1997: 270). El acuerdo entre Administraciones diferentes reproduce un sistema de rivalidad entre gobiernos autonómicos y locales con el fin de que oferten un conjunto de bienes y servicios públicos más adecuado para los/as ciudadanos. La competición crea diferencias en el coste fiscal para la población provocando que ésta resida en la $\mathrm{Co}$ munidad que mejor satisface sus preferencias. Pero en el caso de las políticas de servicios sociales el efecto de la descentralización fiscal suele tener poca relación con la movilidad de la población que depende de esa atención social.

El análisis del Plan Concertado ofrece evidencia de que un sistema descentralizado a partir de un acuerdo entre Administraciones reproduce un sistema generador de desigualdades a nivel territorial. El sistema de asignación de presupuestos parece depender de las habilidades negociadoras de los/as representantes de las Comunidades Autónomas en negociación con la Administración central. Las conferencias sectoriales que reúnen a los/as responsables de los servicios sociales de cada región son ineficientes en la toma de decisiones. El resultado de ese modelo favorece los desequilibrios entre regiones y además reproduce cierta descoordinación en la asignación de las competencias: "De esta forma las políticas concretas que, dentro de su ámbito territorial, desarrolla un ente subcentral no tienen por qué coincidir con las de otro ente subcentral" en otra Comunidad Autónoma (CORONA y PuY, 1998: 3). La descentralización no favorece políticas de equidad ${ }^{8}$. Se fomenta un modelo asimétrico, que explicaría el Plan Concertado como un modelo resultado del federalismo dual que le caracteriza, ya que cada nivel de gobierno ejerce las competencias que la Constitución le atribuye autónomamente respecto de los demás poderes territoriales.

En las páginas que siguen se analiza la evolución de casi una década de Plan Concertado con un especial énfasis en la distribución de los costes en cada Comunidad Autónoma. Se observa el proceso de balcanización de la red básica de servicios sociales, es decir, el resultado de la distribución de los recursos entre las Comunidades Autónomas que forman la red. En 1995 se consolida la tendencia a que las Corporaciones Locales colaboren más en los presupuestos para servicios sociales en comparación con las Comunidades Autónomas, y éstas en mayor medida que la proporción del Ministerio de Trabajo y Asuntos Sociales. Los servicios sociales requieren una organización administrativa que facilite a la población el acceso a los servicios sociales. El protagonismo y participación creciente de las Corporaciones Locales supone un servicio más visible y directo. Son los ayuntamientos y los distritos de los barrios los que adquieren cada vez mayor protagonismo en la gestión de la atención social. Pero el coste de esa descentralización conlleva una descoordinación mayor entre las acciones del MiTAS (Ministerio de Trabajo y Asuntos Sociales) y las acciones de los Ayuntamientos. En la Tabla 1.1 se presenta la evolución de la distribución de los datos referentes al porcentaje del presupuesto en que participa cada Administración pública del Plan Concertado. Se observa que en 1995 el presupuesto total es 40 veces superior al presupuesto en 1988 en datos absolutos. Pese a este incremento del crédito, las diferentes Administraciones mantienen aproximadamente el mismo protagonismo en la distribución del coste ya desde el inicio del sistema ${ }^{9}$. En 1988 el Ministerio de Asuntos Sociales (MAS) colabora con un 26\% del presupuesto total. Los primeros años el porcentaje se mantiene entre el 20 y el 26\% (exceptuando 1989). Posteriormente decrece progresivamente hasta que en 1994 se estabiliza alrededor del $18 \%$ del coste total. Es en ese año cuando el MiTAS costea menos el Plan Concertado. En 1995 el MiTAS parece que se recupera en su participación, pero la tendencia es a descentralizar competencias en las que la Administración Central (los Ministerios) es tradicionalmente fuerte.

Las Comunidades Autónomas, que son las instituciones puente entre el MiTAS y las Corporaciones Locales, pierden también protagonismo en la financiación respecto de los primeros años (su financiación debe ser igual o superior a la de las Comunidades Autónomas). Al inicio del período se observa que las Comunidades Autónomas monopolizan los gastos junto a las Corporaciones Locales (en 1988 es el 33\% del total de los costes). Las Comunidades Autónomas y el MiTAS dan paso a las Corporaciones Locales como protagonistas principales de los gastos. Al inicio del período las Comunidades se estabilizan en un 33\% de los costes del sistema. Posteriormente, de forma casi paralela al MiTAS va disminuyendo los gastos a favor de las Corporaciones Locales. En algunas Comunidades este porcentaje se acerca al 80\% del total (como en Islas Baleares). En otras regiones, sobre todo en las menos ricas, el MiTAS y las Comunidades siguen cubriendo la mayor parte de los gastos.

En la España de fin del siglo XX las Corporaciones Locales se convierten en la institución central en el reparto de los presupuestos para servicios sociales primarios. En 1988 las Corporaciones Locales costean cerca del $40 \%$ del total, y en ocho años es la mitad. Desde el inicio del sistema las Corporaciones. Locales costean un 20\% más del presupuesto total. Se puede 
Tabla 1.1

Evolución de la aportación económica de las diversas Administraciones Públicas

(En porcentajes)

\begin{tabular}{|c|c|c|c|c|c|c|c|c|c|c|}
\hline \multirow{2}{*}{ Crédito asignado por } & \multicolumn{9}{|c|}{ Años } & \multirow{2}{*}{$\begin{array}{c}1995 \\
1998=100\end{array}$} \\
\hline & 1988 & 1989 & 1990 & 1991 & 1992 & 1993 & 1994 & 1995 & 1996 & \\
\hline Ministerio de Asuntos Sociales & $26 \%$ & $21 \%$ & $26 \%$ & $25 \%$ & $24 \%$ & $21 \%$ & $18 \%$ & $17 \%$ & $20 \%$ & 65 \\
\hline Comunidades Autónomas & 33 & 33 & 33 & 32 & 32 & 27 & 28 & 23 & 30 & 70 \\
\hline Corporaciones Locales & 41 & 45 & 40 & 40 & 40 & 49 & 51 & 60 & 50 & 146 \\
\hline \multirow[t]{2}{*}{ Total $^{(a)}$} & $100 \%$ & & & & & & & & & \\
\hline & $(5.830)$ & (11.834) & (20.990) & (29.354) & $(32.690)$ & $(40.487)$ & (45.744) & (48.831) & $(54.190)$ & 458 \\
\hline
\end{tabular}

Fuentes: Ministerio de Trabajo y Asuntos Sociales, Memoria anual 1994, previsiones 1995. Plan Concentado de Prestaciones Básicas en Corporaciones (Madrid: Ministerio de Trabajo y Asuntos Sociales, 1996), p. 178.

Notas: (a) En millones de pesetas. No se incluyen remanentes.

plantear el papel que tiene el protagonismo mayor de las Corporaciones Locales en la baja productividad, y en los costes en cada Comunidad Autónoma. Si se tienen en cuenta los datos sobre el número de personas atendidas, al inicio del sistema (tras su verdadera puesta en marcha) se atiende cada vez a menos personas. El período más productivo coincide con que el Ministerio tiene más protagonismo junto con las Comunidades Autónomas. Posteriormente, a medida que las Corporaciones Locales se responsabilizan del coste del sistema, éste reduce la productividad $^{10}$. Además, los costes a menudo no presentan una relación atransparente. con otros indicadores.

Es. preciso averiguar si la descentralización por Comunidades Autónomas se debe a criterios objetivos sociodemográficos y económicos, a estrategias ideológicas frente a la exclusión social, o si supone un sistema ineficaz para distribuir los recursos de forma equitativa. La descentralización genera desequilibrios y agravios comparativos" entre regiones debido no sólo a las diferentes situaciones de partida en el bienestar, sino a los modos de financiación dependientes del equilibrio de fuerzas politicas (Rodríguez Cabrero, 1998: 139). Las preferencias en la distribución del coste varían significativamente en cada Comunidad Autónoma. Mientras que se observan casos en que la distribución es más regular y homogénea en torno a la media (Galicia, Andalucía, Asturias) existen Comunidades Autónomas con pautas de gasto diferentes (Cataluña y Cantabria). La forma antitética en las estrategias de gasto es posible que se deba a que las regiones presentan características socioeconómicas diferentes, es decir, que presenta necesidades institucionales diferentes. Se parte del supuesto que la dispersión y la desigualdad del sistema sea el resultado de un sistema que genera desigualdades entre regiones porque el mecanismo basado en los protocolos suscritos bilateralmente es de por sí generador de desigualdades. Las Comunidades que se alejan de la media (tanto positiva como negativamente) se interpretan como un rasgo perverso del propio sistema.

El proceso de descentralización que se inicia por separado en cada Comunidad Autónoma hace difícil comprender la red como un sistema coordinado, aun más si existen implicaciones políticas y niveles de descentralización diferentes en cada Comunidad Autónoma. Los casos outliers debido a su particularidad en la gestión de los servicios sociales cuestionan la lógica global del sistema marcada desde el Ministerio. Un análisis a partir de índices compuestos incluye en el análisis multitud de indicadores de necesidad. Un ejemplo de estudio a partir de índices compuestos es el análisis de Robert Putnam sobre la institutional performance de los gobiernos de las regiones de Italia. PutNam analiza los factores que son determinantes en las diferencias institucionales entre el norte italiano cosmopolita y rico, y el sur tradicionalmente pobre. Los índices compuestos explican las diferencias en la respuesta institucional frente a las necesidades de la población. Para el caso de los servicios sociales en España la asignación de recursos debe contemplar otras variables claves como: el número de casos de mujeres maltratadas, los casos de transeúntes sin hogar y los problemas de la ancianidad.

Los datos de las Comunidades Autónomas se ordenan según la renta per capita de cada Comunidad para comprobar la distribución de los recursos por personas atendidas en cada región. Es un análisis vertical sobre los efectos de la descentralización en la provisión de servicios sociales. Se apuesta así por un análisis detallado y con datos que mida la eficiencia en la distribución de los recursos. En el análisis de la distribución de la renta para servicios sociales son de especial interés las Comunidades 
Autónomas que reciben el Fondo Compensatorio Interterritorial, que incluyen a: Extremadura, Andalucía, Castilla-La Mancha, Galicia, Murcia, Canarias, Castilla y León, Valencia y Asturias. Este fondo se destina a las Comunidades Autónomas menos ricas para desarrollar servicios de transporte y comunicaciones, vivienda rural, infraestructuras para la provisión de agua, etc. Es un indicador indirecto y un reconocimiento institucional de las áreas más deprimidas de España. En la Tabla 1.2 se observa que el coste supera los 45 mil millones de pesetas. Se destina al personal y a los servicios que se realizan una parte importante de los recursos económicos del Plan Concertado. Se observa que el Plan Concertado destina el presupuesto mayor a las partidas de personal y prestaciones; el mantenimiento y las inversiones son las partidas con un coste menor.

\section{Tabla 1.2}

Distribución del coste de partidas segin Comunidades Autónomas, en 1994

\begin{tabular}{|c|c|c|c|c|c|c|c|c|c|c|}
\hline \multirow{2}{*}{$\begin{array}{l}\text { Comunidades } \\
\text { Autónomas }\end{array}$} & \multicolumn{2}{|c|}{ Total } & \multicolumn{2}{|c|}{ En prestaciones } & \multicolumn{2}{|c|}{ En personal } & \multicolumn{2}{|c|}{ En mantenimiento } & \multicolumn{2}{|c|}{ En inversiones } \\
\hline & Coste & $\%$ & Coste & $\%$ & Coste & $\%$ & Coste & $\%$ & Coste & $\%$ \\
\hline Islas Baleares & 1.446 & $100 \%$ & 551 & $38 \%$ & 852 & $59 \%$ & 37 & $3,0 \%$ & 6 & - \\
\hline La Rioja & 325 & & 175 & 54 & 49 & 15 & 0.82 & - & 100 & 31 \\
\hline Comunidad de Madrid & 5.708 & & 3.734 & 65 & 1.416 & 25 & 164 & 3,0 & 394 & 7,0 \\
\hline Comunidad Valenciana & 4.490 & & 3.245 & 72 & 1.141 & 25 & 105 & 2,0 & - & - \\
\hline Aragon & 1.402 & & 620 & 44 & 692 & 49 & 90 & 6,0 & - & - \\
\hline Principado de Asturias & 1.563 & & 839 & 54 & 585 & 37 & 106 & 7,0 & 33 & 2,0 \\
\hline Región de Murcia & 2.024 & & 998 & 49 & 876 & 43 & 150 & 7,0 & - & - \\
\hline Canarias & 2.343 & & 1.118 & 48 & 1.079 & 46 & 146 & 6,0 & - & - \\
\hline Castilla-La Mancha & 1.950 & & 378 & 19 & 1.264 & 65 & 302 & 15 & 7 & - \\
\hline Andalucia & 11.826 & & 5.456 & 46 & 5.464 & 46 & 643 & 5,0 & 263 & 2,0 \\
\hline Extremadura & 762 & & 216 & 28 & 467 & 61 & 79 & 10 & - & - \\
\hline Total & $45.708^{\circ}$ & $100 \%$ & 21.548 & $47 \%$ & 20.448 & $45 \%$ & 2.492 & $5,0 \%$ & 1.223 & $3,0 \%$ \\
\hline
\end{tabular}

Fuentes: Ministerio de Trabajo y Asuntos Sociales, Memoria antual 1994, previsiones 1995. Plan Concertado de Prestaciones Básicas en Corporaciones Locales (Madrid: Ministerio de Trabajo y Asuntos Sociales, 1996), p. 261.

El coste en prestaciones supone en algunas Comunidades Autónomas una Proporción del coste total cercana al $90 \%$. De las Comunidades Autónomas más ricas, Cataluña y La Rioja son las que asignan un coste menor a esa partida. Cataluña sigue una estrategia en la distribución de los costes contraria al resto de las Comunidades que forman la red. Mientras que la media de coste en prestaciones se sitúa alrededor de la mitad del presupuesto, Cataluña destina a esta partida sólo un 5\%. Las Comunidades Autónomas medias en renta suelen destinar una proporción mayor del coste que la media del Plan Concertado. Cantabria supone un $88 \%$ del coste total en prestaciones, siendo la Comunidad Autónoma que destina una proporción mayor del presupuesto a ese apartado. Las Comunidades Autónomas menos ricas destinan un coste menor que la media total del sistema. ¿Cuál es la razón por la qué en una Comunidad Autónoma se destina un coste mayor para personal y en otras más coste a prestaciones? La evidencia empírica muestra que existe una Relación entre el grado de inversión en las prestaciones de servicios sociales con el nivel de desarrollo económico en cada Comunidad Autónoma. En las Comunidades Autónomas ricas se invierten menos recursos en prestaciones sociales, pese a que la cantidad total de recursos per capita es mayor.

Las Comunidades Autónomas con mayor renta per capita (Islas Baleares, Cataluña, La Rioja y la Comunidad Autónoma de 
Madrid) destinan el coste a partidas de forma desigual. Mientras que Islas Baleares y Cataluña distribuyen un $60 \%$ y $80 \%$, respectivamente, al capítulo de personal, La Rioja y Madrid alcanzan un $15 \%$ y $25 \%$. De las ocho Comunidades intermedias Galicia alcanza el $50 \%$ y es significativo que la Comunidad Autónoma de Cantabria sólo destine a este capítulo un $8 \%$. El resto destinan aproximadamente entre un $25 \%$ y un $45 \%$. Las Comunidades Autónomas menos ricas son las que junto con Baleares y Madrid destinan mayor porcentaje a esa partida. Esta desigualdad en las preferencias supone que en cada Comunidad Autónoma se plantean estrategias distintas en el reparto de recursos. Estas diferencias porcentuales reproducen el sistema balcanizado en el que cada Comunidad Autónoma se marca sus objetivos de gasto sobre el presupuesto por su cuenta y sin un análisis comparativo.

El coste en mantenimiento varía poco entre las regiones del Plan Concertado. Las dos Castillas son los polos del sistema en esa partida del presupuesto. Castilla-La Mancha destina un 15\% al mantenimiento mientras que Castilla y León sólo supone un $2 \%$ del coste total. La media se sitúa en un $5 \%$ representando dos mil millones de pesetas. Aunque existen algunas excepciones la tendencia es que las Comunidades Autónomas menos ricas destinen más coste a esta partida que las ricas. Es significativo el $10 \%$ que destina Extremadura a esta partida, ya que esta proporción es muy elevada en comparación con el resto de Comunidades. Precisamente en Extremadura en la que se destinan menos recursos per capita en comparación a otras regiones, y en la que existen poblaciones que no reciben atención por la dispersión de su población; la red presenta un coste más elevado en mantenimiento. En las Comunidades Autónomas con servicios sociales tradicionalmente más desarrollados, al inicio del sistema invierten más en prestaciones y personal. Se ponen en marcha las infraestructuras más necesarias a nivel de servicios (prestaciones) y personal (trabajadores sociales) para posteriormente acondicionar (mantenimiento) y realizar otras inversiones (creación de nuevos centros de servicios sociales).

El coste en inversiones es la partida que menos proporción supone respecto del coste total del Plan Concertado. En algunas Comunidades Autónomas (Comunidad Valenciana, Aragón, Cantabria, Murcia, Canarias y Extremadura) el coste en inversiones es casi inexistente. Sorprende que la Comunidad Autónoma de La Rioja destine un $31 \%$ del coste a inversiones, suponiendo una variación importante respecto al resto de $\mathrm{Co}_{0}$ munidades. Las inversiones muestran cierta saturación en la expansión del Plan Concertado. Esas inversiones tienen escasa relación con la proporción de población cubierta en cada región. La red cubre a poca población en Castilla-La Mancha y Comunidad Valenciana; y en esas Comunidades Autónomas tampoco se producen inversiones. Todo hace suponer que el sistema no invierte en centros nuevos o programas precisamente en las zonas geográficas que más lo necesitan. La lógica del sistema tampoco parece responder a modelos predefinidos del gasto.

La distribución regional no sigue una pauta clara. Las Comunidades Autónomas que suponen los polos del sistema se comportan de forma similar. Extremadura, la más pobre, destina un coste del $61 \%$ al capítulo del personal e Islas Baleares, la más rica, un $59 \%$. El mantenimiento supone un $3 \%$ y un $10 \%$, y las prestaciones un $38 \%$ y $28 \%$, respectivamente. Son dos ejemplos que se adecuan a la media. Hay que explicar el motivo de esas variaciones y estudiar las razones de la ausencia de inversiones en nuevos edificios y mejoras de los centros. Las proporciones bajas de coste en mantenimiento explicarían que los Centros de Servicios Sociales, los Albergues y los Centros de Acogida estén en condiciones buenas (muchos de los centros creados son nuevos). El elevado coste de las prestaciones supone inversiones en la mejora de los servicios realizados más tecnificados y con personal más eficiente. Los servicios sociales están cada vez más profesionalizados. Existen Comunidades Autónomas que presentan unas preferencias en el gasto desmarcadas de la tendencia global ${ }^{11}$. El reparto de los créditos sigue las directrices marcadas desde las Corporaciones Locales, pero en el caso de las Islas Baleares y Extremadura las estrategias marcadas sorprendentemente no son necesariamente opuestas. Extremadura que está gestionada principalmente por el MiTAS presenta una distribución del coste similar a Islas Baleares gestionada desde las Corporaciones Locales.

El nivel bajo de inversiones es una constante en el Plan Concertado. La Rioja es una excepción puesto que destina un $31 \%$ a este capítulo (en términos absolutos no es mucho dinero). Es un indicador que expresa cierta saturación en la expansión. Por el contrario, la Comunidad Valenciana y Castilla-La Mancha poseen niveles bajos de municipios y población cubierta. Es necesario que se realice un esfuerzo para ofrecer servicios nuevos adecuados a las Comunidades Autónomas y en los municipios más pequeños. En la Comunidad Valenciana se cubre a un $58 \%$ de la población, que equivale sólo a un $13 \%$ de municipios. El caso de Castilla-La Mancha es igualmente signiffcativo donde un $8 \%$ de municipios están cubiertos, pese a que la proporción de población atendida es mayor (64\%). Se trata quizás de un problema de productividad. Una primera hipótesis es que los servicios sociales públicos están más desarrollados en aquellas regiones con mayor concentración de población en sus capitales. Habría que tener en cuenta el posible solapamiento en la oferta de servicios sociales entre el sector privado y el sector público.

Para el análisis de la distribución de los costes se aplica la fórmula del coeficiente de variación acotado. La Tabla 1.3 presenta las desigualdades en la distribución de las partidas de re- 


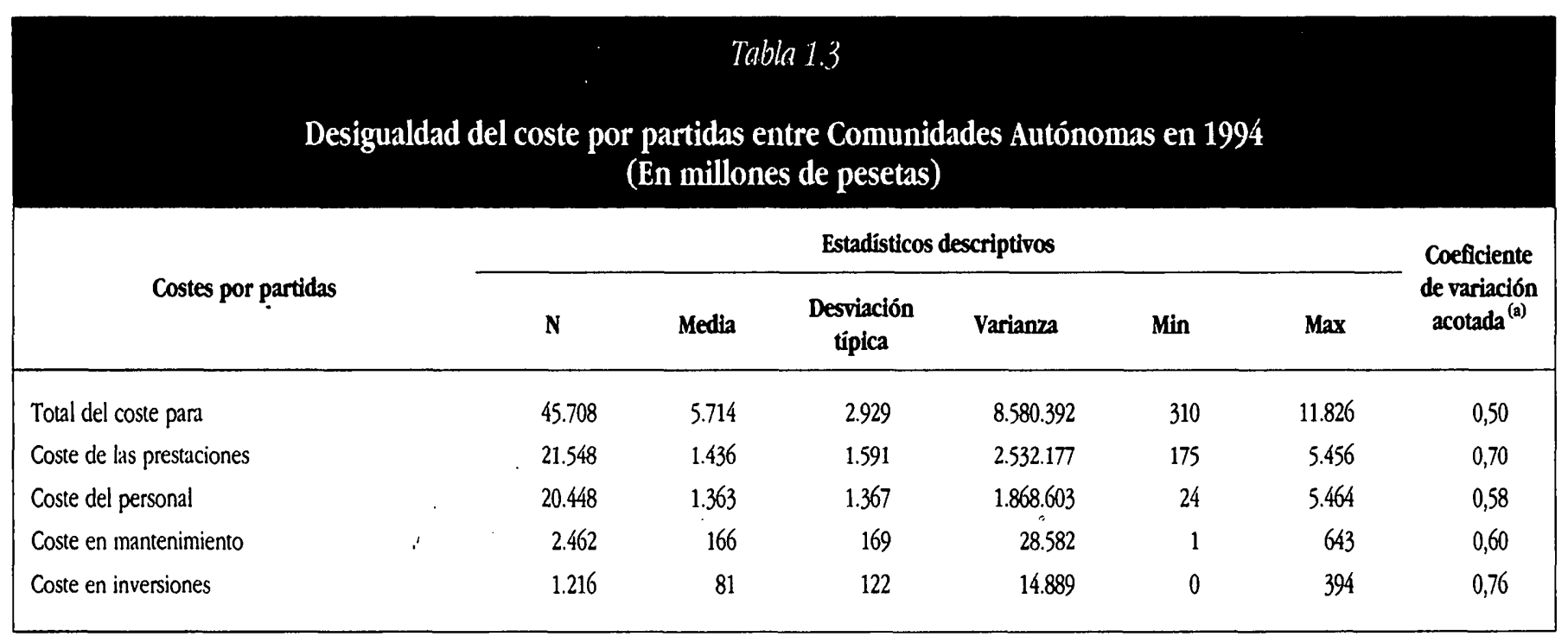

Nocas: (a) El coeficiente de variación acotado es igual a la raiz cuadrada del coeficiente entre la desviación úpica y la variación máxima que se halla aplicando la fórmula

$\operatorname{Var}_{\max }=\left(\bar{X}-\mathrm{X}_{\min }\right)^{\bullet}\left(\mathrm{X}_{\max } \mathrm{X}\right)$. Véase Escobar, Modesto, .Desviación, desigualdad, polarización: Medidas de la diversidad social, Revista de Investigaciones Sociológicas 82 (1998), pp. 9-36.

cursos de servicios sociales en las Comunidades Autónomas. Se aplican estadísticos que evalúan la dispersión en la distribución de las partidas (desviación típica y varianza) para, así, analizar la desigualdad en el reparto de los recursos. Se aplica el coeficiente de variación de Pearson corregido por coeficiente de variación acotado ${ }^{12}$. Ambos indicadores superan las limitaciones de estadísticos como la media, la desviación típica y la varianza que no permiten la comparación de indicadores medidos con unidades distintas. El coeficiente de variación acotado utiliza la varianza máxima que se obtiene de la resta entre el valor mínimo de la distribución y su media, multiplicado por el resultado de la resta entre el valor máximo de la distribución y su media. La proporción de variación acotada tiene en cuenta la distribución de los datos. El coeficiente de variación queda acotado en un rango entre 0 y 1 que supone el valor mínimo y el valor máximo de cada índice.

Pese a que los datos están medidos en las mismas unidades (en miles de pesetas), el coeficiente de variación acotado añade aquí precisión al considerar los valores mínimos y máximos de cada uno de los indicadores de la distribución de los recursos sobre las partidas presupuestarias en las quince Comunidades Autónomas estudiadas. La media del sistema se sitúa en 5.714 millones de pesetas por Comunidad Autónoma. Sólo las Comunidades de Madrid y Andalucía superan la media de una distribución del coste total que presenta una desviación típica que se sitúa en 2.929 millones. Los polos del sistema son Andalucía con más de 11 mil millones de pesetas y Cantabria con aproximadamente 300 millones.

La dispersión y desigualdad no necesariamente supone un indicador negativo de distribución de recursos, pues falta comprobar si el grado de dispersión responde a las necesidades co- yunturales de cada región. Se observa, sin embargo, que de las cuatro partidas la que presenta un coeficiente de variación acotado mayor respecto a la media del sistema $(0,77)$ son las inversiones que es el indicador que más fluctúa entre las quince Comunidades estudiadas. El coeficiente de dispersión elevado sugiere que en esa Comunidad se invierte más en servicios sociales mientras que en otras esas inversiones son nulas. Es difícil pensar que al cabo del año no se realicen inversiones en una Comunidad, es una pauta que las Administraciones no suelen desaprovechar. La inversión nula es el resultado de que en términos absolutos los servicios sociales cuentan con recursos escasos. Sólo se invierte en las Comunidades muy descentralizadas y con recursos o en Comunidades que por su extensión y población el presupuesto es lo suficientemente sustancioso como para promoveer un ainterés" institucional. Las prestaciones que alcanzan un coeficiente de variación de 0,71 . El mantenimiento presenta un coeficiente de variación acotado de 0,60 y el personal de 0,58. El sistema es pues más desigual en la distribución de recursos en las partidas de prestaciones e inversiones, mientras que es más equitativo en personal y mantenimiento. El total del coste presenta un coeficiente de variación de 0,51 que supone que existe una variación del $51 \%$ en la distribución de los recursos entre las Comunidades Autónomas que forman el Plan Concertado. Este indicador es especialmente útil para observar la evolución en la dispersión de los recursos en períodos largos de más de diez años. Falta comprobar si la dispersión del presupuesto absoluto se mantiene controlando el peso relativo de la población, los proyectos por cien mil habitantes, coste por persona, el coste por persona àtendida, y el color político de los gobiernos de las Comunidades Autónomas. El sistema presenta una fuerte dispersión en los recursos, falta comprobar si la dispersión afec- 
ta a la cantidad de recursos en función del grado de descentralización interna entre Administraciones (desigualdad vertical), y a las diferencias que se establecen entre usuarios de un mismo servicio pero en Comunidades diferentes (desigualdad horizontal).

\section{Desigualdades regionales y descentralización de recursos}

Las políticas de servicios sociales de atención primaria se desarrollan en función de la voluntad política en el desarrollo de las competencias asumidas por cada Comunidad Autónoma. El análisis muestra las diferencias entre grupos de cinco Comunidades. La lista está encabezada por las Islas Baleares, la Comunidad Autónoma más rica, y la cierra Extremadura como la menos rica. Se muestra la relación entre el tipo de gobierno y la renta per capita, con relación al reparto del crédito asignado dentro del Plan Concertado. La Tabla 1.4 presenta los datos ordenando las Comunidades Autónomas según su renta per capita, señalando la distribución territorial. Se incluyen tres variables fundamentales: la población de hecho según el censo (de 1991), la renta per capita en miles de pesetas (año 1994), y el tipo de Gobierno autonómico (en el año 1992). Se ofrece una relación de la población de cada Comunidad Autónoma comparando la población de hecho en esa Comunidad Autónoma con la renta per capita correspondiente.

\section{Tabla 1.4}

\section{Población, renta y tipo de gobierno en las Comunidades Autónomas en 1992 y 1993}

\begin{tabular}{|c|c|c|c|c|c|}
\hline Islas Baleares & 745.944 & 124 & 114 & $\mathrm{PP}$ & PP \\
\hline Cataluña & 6.115 .579 & 123 & 118 & $\mathrm{CiU}$ & $\mathrm{CiU}$ \\
\hline Comunidad de Madrid & 5.030 .958 & 109 & 114 & PSOE & PSOE \\
\hline Comunidad Valenciana & 3.923 .841 & 108 & 103 & PSOE & PSOE \\
\hline Comunidad Foral de Navarra & 523.563 & . 107 & 116 & $\mathrm{UPN}^{(\mathrm{a})}$ & $\mathrm{PP}$ \\
\hline Aragón & 1.221 .546 & 106 & 107 & PSOE & PAR \\
\hline Galicia & 2.720 .445 & 94 & 79 & PP & $\mathrm{pp}$ \\
\hline Castilla y León & 2.562 .979 & 93 & 96 & $\mathrm{Pp}$ & PP \\
\hline Región de Murcia & 1.059 .612 & 92 & 86 & PSOE & PSOE \\
\hline Canarias & 1.673 .641 & 90 & 97 & PSOE & PSOE \\
\hline Castilla-La Mancha & 1.651 .883 & 87 & 77 & PSOE & PSOE \\
\hline Andalucía & 7.040 .627 & 82 & 77 & PSOE & PSOE \\
\hline Ceuta y Melilla & 136.878 & 79 & $79^{(c)}$ & PSOE & PSOE \\
\hline Extremadura & 1.056 .538 & 76 & 76 & PSOE & PSOE \\
\hline Total & 39.469 .992 & $100^{(\mathrm{a})}$ & 100 & PSOE & PSOE \\
\hline
\end{tabular}

Fuentes: Instituto Nacional de Estadística, Poblaciones de derecho y de hecho referidas a uno de marzo de 1991 por Comunidades Autónomas (Madrid: INE, 1991), pp. 129-130. INE, Panorámica Social (Madrid: INE, 1994), p. 422. Los datos corresponden a la Contabilidad Regional de España, del INE. El País, Anuario El País (Madrid: Ediciones El País, 1996), p. 445. Notas: (a) Unión del Pueblo Navarro.

(b) Se considera 100 la media nacional de la renta familiar disponible por habitante.

(c) Se uitiza el de 1992, pues el de 1993 es desconocido. 


\section{Tabla 1.5}

\section{Proyectos y créditos de cada Comunidad Autónoma en 1993}

\begin{tabular}{|c|c|c|c|c|c|c|}
\hline Islas Baleares & & 8 & 1,1 & 1.334 & 167 & 1.792 \\
\hline Cataluña & & 83 & 1,4 & 3.761 & 45 & 615 \\
\hline Comunidad de Madrid & & $37^{\circ}$ & 0,7 & 7.308 & 198 & 1.453 \\
\hline Comunidad Valenciana & & 12 & 0,3 & 2.593 & 216 & 661 \\
\hline Aragón & & 72 & 5,9 & 1.254 & 17 & 1.026 \\
\hline Principado de Asturias & & 32 & 2,9 & 1.377 & 43 & 1.253 \\
\hline Región de Murcia & & 23 & 2,2 & 1.113 & 48 & 1.066 \\
\hline Canarias & & 81 & 4,9 & 1.966 & 24 & 1.175 \\
\hline Castilla-La Mancha & & 73 & 4,4 & 1.932 & 26 & 1.170 \\
\hline Andalucia & & 200 & 2,9 & 9.618 & 48 & 1.366 \\
\hline Extremadura & 1 & 73 & 6,9 & 754 & 10 & 714 \\
\hline Total & & 815 & 2,0 & 41.016 & 50 & 1.118 \\
\hline
\end{tabular}

Fuentes: Instituto Nacional de Estadística, Poblaciones de derecbo y de becho referidas a uno de marzo de 1991 por Comunidades Autónomas (Madrid: INE, 1991 ), pp. 129-130. INE, Panorámica Social (Madrid: INE, 1994), p. 422. Los datos corresponden a la Contabilidad Regional de España, del INE. El País, Anuario El Pais (Madrid: Ediciones El País, 1996), p. 464.

Notas: (a) No incluye la Comunidad Foral de Navarra, el Páis Vasco, Ceuta y Melilla.

Como se aprecia en el análisis de las correlaciones, existe una relación estadística positiva entre el tipo de gobierno y la renta familiar disponible ${ }^{13}$. En 1992 la media de la variable tipo de gobierno se sitúa en el 4,5 en un eje izquierda-derecha. Un año después el tipo de gobierno se sitúa en ese eje en 5,1, es decir las Comunidades Autónomas tienden a ser más conservadores. Llama la atención que a mayor renta per capita el gobierno de la Comunidad Autónoma sea más conservador (o viceversa). Existe una correlación del 0,37 entre la renta familiar y el tipo de gobiemo autonómico de 1992 y de 0,42 entre la renta familiar disponible y el tipo de gobierno en 1993.

Al analizar la distribución de los créditos asignados y los proyectos de cada Comunidad Autónoma en 1993 se observia que cada Comunidad Autónoma supone una realidad diferencial. Los datos de la Tabla 1.5 incluyen en el análisis el número de proyectos por Comunidad Autónoma, tasa de proyectos por cada cien mil habitantes, el crédito asignado, la media del crédito asignado en millones de pesetas y el crédito asignado por habitante. Se observa que en 1993 se adjudican un total de 815 proyectos entre todas las Comunidades Autónomas. En ese año por cada cien mil habitantes se adjudica una media de dos proyectos. El crédito asignado en 1993 supera los 40 mil millones de pesetas. Cada proyecto recibe una media de 50 millones de pesetas, y la media por habitante es aproximndamente de 1.200 pesetas. Esos 50 millones coinciden con el coste global por centro, lo que sugiere que aproximadamente la puesta en marcha de un centro nuevo es igual a un proyecto.

Las Comunidades que mayor número de proyectos se le asignan son (por orden de mayor a menor): Andalucía, Galicia, Canarias y Cataluña. Son dos Comunidades Autónomas menos ricas (Andalucía y Galicia), una media (Canarias) y una rica (Cataluña). Las que menor número de proyectos se. les asignan son: Islas Baleares, La Rioja y Cantabria. Son dos Comunidades Autónomas ricas y una media. Se observa, pues, que en líneas generales las Comunidades pobres reciben una tasa mayor de proyectos que las ricas, con una progresión similar a los proyectos por cien mil habitantes. Alrededor de la mitad de los proyectos se destinan a las Comunidades más pobres en las 
que la gestión está en manos de la Administración central; pero aun así se reproducen las desigualdades territoriales, sobre todo en el crédito asignado por proyecto en cada Comunidad.

La distribución de los proyectos por cien mil habitantes varía ligeramente pero sigue manteniendo una tendencia favorable a las Comunidades menos ricas como destinatarias del mayor número de proyectos. Las que más proyectos reciben (por orden) son: Extremadura, Aragón, Canarias, y Castilla-La Mancha. A excepción de Aragón (rica) y Cantabria (media), el resto son Comunidades menos ricas. Por el contrario, las Comunidades a las que se les asigna un número menor de proyectos son: Comunidad de Madrid (rica), Comunidad Valenciana (media), Islas Baleares (rica), y Castilla y León (media). Se observa pues que las Comunidades Autónomas más pobres a excepción de la región de Murcia todas ellas superan la media de 2,3 proyectos por cien mil habitantes. La tendencia sigue criterios estructurales en que se priorizan las Comunidades menos ricas frente a las más ricas, a excepción de Castilla y León este indicador muestra que la región de Murcia, Extremadura y Andalucía están desfavorecidas en número de proyectos por cien mil habitantes.

El crédito asignado para 1993 presenta irregularidades en la distribución de recursos entre las regiones estudiadas. El crédito se distribuye de mayor a menor entre: Andalucía (pobre), la Comunidad de Madrid (rica), y Castilla y León (media). Se observa que no se sigue ningún criterio explicito para el reparto del crédito. Se incumple incluso el criterio de asignación de recursos por población y por criterios de pobreza relativa. El caso más sorprendente es el de Extremadura que siendo la Comunidad más pobre de España es la segunda que menos crédito recibe en números absolutos. Por el contrario, los casos de la Comunidad de Madrid, Islas Baleares, Cataluña y Aragón sorprenden, ya que siendo Comunidades ricas reciben una parte más que proporcional del crédito asignado. Esto se debe seguramente a la importancia de la concentración de población en las capitales de provincia, junto a los problemas sociales de centros urbanos como Madrid y Barcelona. La distribución desigual sugiere que el reparto se realiza de acuerdo a presiones y negociación política entre los diversos niveles y territorios implicados.

La media de crédito asignado por proyecto evidencia la forma en que se reparte el crédito, según si el número de proyectos de cada Comunidad Autónoma es mayor o menor. Una sorpresa es que la asignación de los proyectos sigue criterios más igualitarios que la asignación de los créditos. La media que se presenta sitúa a Comunidades Autónomas como Islas Baliéares y la Comunidad de Madrid con una media de crédito por proyecto elevada respecto de la media española. Sorprendentemente las Comunidades más pobres reciben todas ellas el crédito asignado por debajo de la media de las Comunidades Autónomas. Mucho crédito para pocos proyectos sería la ten- dencia en las Comunidades Autónomas más ricas, mientras que en las pobres muchos proyectos se reparten poco presupuesto. Los servicios en las Comunidades ricas son mejor dotados puesto que a cada proyecto se destina mayor presupuesto. Es importante comprobar las fórmulas distributivas de los créditos por Comunidades pues la relación entre crédito y eficiencia puede ser mediada por otras variables exógenas como son los indicadores objetivos de necesidad de cada Comunidad aunque éstos son muy difíciles de medir bien ${ }^{14}$.

La variable fundamental es la de la última columna de la tabla. El crédito asignado por habitante muestra que las cuatro Comunidades que más crédito reciben por habitante son Islas Baleares (rica), Castilla y León (pobre), Comunidad de Madrid (rica) y Andalucía (pobre). El reparto es más favorable entre las Comunidades más ricas, que reciben un crédito por habitante superior a las mil pesetas por persona y año para recursos públicos en servicios sociales. El sistema no parece que financie excesivamente a unas Comunidades Autónomas, sino que algunas están poco financiadas. Exceptuando a la Comunidad Autónoma de Extremadura, Cataluña, la Comunidad Valenciana y Cantabria, el resto supera las mil pesetas de media por persona. Pese a estos datos, el Plan Concertado presenta una distribución confusa pues existen lagunas, áreas con poca inversión pública que dificultan la comprensión del reparto.

Sería importante estudiar con detalle casos como el de Islas Baleares en que se supone que es un sistema en el que es posible que se deriven fondos hacia otras partidas, como por ejemplo al turismo. Pero lo más interesante es realizar un análisis detallado de las Comunidades Autónomas extremas: Islas Baleares (la más rica y al mismo tiempo la que más crédito tiene) y Extremadura (la más pobre, y paradóicamente con los créditos más bajos). Los primeros resultados muestran que las Comunidades más ricas son las. Comunidades históricamente con más poder de negociación, como la Comunidad de Madrid y la de Cataluña. El caso de las Islas Baleares se explica por la relación cultural con Cataluña que supone un punto de referencia para esa Comunidad en muchas de sus reformas ${ }^{15}$.

En la Tabla 1.6 se presenta la aplicación del coeficiente de variación acotado. Se observa que el indicador que presenta mayor variación es la media de crédito asignado por proyecto. Significa que el sistema presenta niveles altos de desigualdad en el reparto del presupuesto sobre todo en el porcentaje de dinero destinado a cada proyecto. El resto de indicadores no baja del 0,60 de coeficiente de variación acotado, que significa que existe una dispersión de más del $60 \%$ en cada uno de los indjcadores de distribución de recursos en cada una de las Comunidades Autónomas. El coeficiente de variación acotado pone en relación los cinco indicadores y los compara, el dato más significativo es que el sistema en su conjunto presenta un nivel alto de desigualdad en la asignación de recursos por proyecto, pro- 
Tabla 1.6

Desigualdad en los indicadores sobre recursos

\begin{tabular}{|c|c|c|c|c|c|c|c|}
\hline \multirow{2}{*}{ Indicadores de recursos } & \multicolumn{6}{|c|}{ Análisis de la dispersión } & \multirow[b]{2}{*}{$\begin{array}{l}\text { Coeficiente } \\
\text { de variación } \\
\text { acotada }^{(2)}\end{array}$} \\
\hline & $\mathbf{N}$ & Media & $\begin{array}{l}\text { Desviación } \\
\text { típica }\end{array}$ & Varianza & Min & $\operatorname{Max}$ & \\
\hline Número de proyectos & 815 & 55 & $51,5^{\circ}$ & 2.651 & 5 & 200 & 0,60 \\
\hline Crédito total asignado en 1993 (en millones de pta.) & 41.016 & 2.735 & 2.640 & 6.971 .032 & 301 & 9.618 & 0,64 \\
\hline Media de crédito por proyecto (en miles de pta.) & \multirow{2}{*}{$\therefore$} & 77 & 70,7 & 5.005 & 10 & 216 & 0,73 \\
\hline Crédito asignado por habitante(año (en pta.) & & 1.122 & 367 & 135.030 & 598 & 1.792 & 0,62 \\
\hline
\end{tabular}

Nocas: (a) El coeficiente de variación acotado es igual a la raíz cuadrada del coeficiente entre la desviación típica y la variación máxima que se halla aplicando la fórmula.

$\operatorname{Var}_{\max }=(\mathrm{X}-\mathrm{X})^{\circ}\left(\mathrm{X}_{\max }-\mathrm{X}\right)$. Véase EscoBar, Modesto, •Desviación, desigualdad, polarización: Medidas de la diversidad social, Revista de Investigaciones Sociológicas 82 (1998), pp. 9-36.

yectos por habitante, crédito asignado, crédito por proyecto y crédito por habitante y año. El Plan Concertado presenta niveles bastante desiguales en la distribución de los recursos, pero es preciso complementarlo con un análisis de la equidad horizontal.

Existe una correlación 0,60 entre el número de proyectos y el crédito asignado para 1993, es decir, estas dos variables están relacionadas linealmente, si una aumenta la otra aumenta en re- lación lineal respecto de la otra -tal y como se muestra en el análisis de correlaciones-. Para un análisis de causalidad esta relación lineal es una condición sine qua non, si bien el que exista una correlación del orden de 0,60 entre el crédito para un año y los proyectos de la Comunidad no presupone necesariamente que esa relación sea causal. Es posible que en la correlación otras variables intervinientes expliquen posibles relaciones causales. Una hipótesis provisional es que en las $\mathrm{Co}_{-}$ munidades Autónomas en las que los servicios sociales están más desarrollados el sistema invierta más crédito. Así pues, que una Comunidad Autónoma lleve varios años desarrollando su sistema de servicios sociales frente a otras Comunidades que se han desarrollado más tarde, puede favorecer en su capacidad para realizar inversiones.

El análisis muestra que el número de proyectos correlaciona negativamente $(-0,44)$ con el crédito por proyecto. Disponer de muchos proyectos significa que cada uno de esos proyectos recibe menos dinero, o viceversa. En aquellas Comunidades en las que existan más proyectos, éstos es posible que acumulen menos dinero para ofrecer campañas y asistencia social. La relación causal debe ponerse de nuevo en cuestión pues las correlaciones sólo establecen la linealidad de dos variables. Una hipótesis intuitiva es que aquellas Comunidades en las que los recursos están centralizados en pocos centros y proyectos reciben más dinero, es decir, el sistema tiende a centralizar recursos en los centros más complejos del sistema.

Una tercera relación muestra la correlación lineal negativa entre el número de proyectos por cien mil habitantes y el crédito por proyecto $(-0,76)$. El sistema tiende a favorecer aquellas Comunidades Autónomas que tienen pocos proyectos por cien mil habitantes. Sorprende que en las Comunidades donde se desarrollan más proyectos de servicios sociales el crédito asignado en millones de pesetas sea menor: Es posible que ese fenómeno se deba a que en las Comunidades en las que se cuenta con gran número de proyectos, son centros pequeños, que no requieren de gran inversión para su funcionamiento y autonomía. No importa el número de centros y proyectos, ni lo grandes que son, sino las campañas que se realizan y su capacidad de asimilar necesidades y problemas de la población. Falta, pues, la comprobación de esos datos con un análisis más detallado de campañas y servicios sociales que nos permitan comprender si el sistema de distribución de los recursos repercute en zonas con más necesidades.

El incremento y/o decremento de los créditos y la tasa de proyectos, se produce de forma independiente en cada Comunidad. Los datos de la Tabla 1.7 muestran la evolución de los créditos y los proyectos de cada Comunidad Autónoma al año siguiente, es decir, en 1994. Sorprende comprobar que Comunidades Autónomas como Baleares y Aragón siguen incrementando el crédito por habitante al año entre un $6 \%$ y un $12 \%$. Por el contrario, las Comunidades Autónomas de Extremadura, Galicia y la Región de Murcia decrecen, o su crecimiento es mínimo ${ }^{16}$. En 1994 el sistema crea once centros más respecto a 1993. Supone un crecimiento del crédito de aproximadamente un $11 \%$. 


\section{Tabla 1.7}

\section{Créditos y proyectos en cada Comunidad Autónoma en 1994}

\begin{tabular}{|c|c|c|c|c|c|c|c|}
\hline Comunidad Autónoma & $\begin{array}{l}\text { Número de } \\
\text { proyectos }\end{array}$ & $\begin{array}{c}\text { Número de } \\
\text { proyectos } \\
\text { por } 100.000 \text { hab. }\end{array}$ & $\begin{array}{c}\text { Crédito asignado } \\
\text { para } 1994 \\
\text { (en millones pta.) }\end{array}$ & $\begin{array}{l}\text { Media de crédito } \\
\text { asignado por } \\
\text { proyecto } \\
\text { (en millones pta) }\end{array}$ & $\begin{array}{c}\text { Crédito asignado } \\
\text { por habitante/año } \\
\text { (en pta.) }\end{array}$ & $\begin{array}{c}\text { Coste para } \\
\text { prestaciones/ } \\
\text { persona atendida } \\
(\text { (en pta.) }\end{array}$ & $\begin{array}{c}\text { Incremento } \\
\text { respecto } \\
\text { de } 1993\end{array}$ \\
\hline Islas Baleares & 7 & 1,1 & 1.421 & 203 & 1.905 & 28.752 & $6,3 \%$ \\
\hline Cataluña & 83 & 1,4 & 3.719 & 45 & 608 & - & $-1,1$ \\
\hline Comunidad de Madrid & 37 & 0,7 & 6.769 & 183 & 1.345 & 36.556 & $-7,4$ \\
\hline Comunidad Valenciana & 28 & 0,7 & 3.939 & 141 & 1.004 & 15.596 & 51,8 \\
\hline Aragón & 72 & 5,9 & 1.402 & 20 & 1.148 & 5.356 & 11,9 \\
\hline Principado de Asturias & 27 & 2,4 & 1.421 & 53 & 1.293 & 18.847 & 3,2 \\
\hline Región de Murcia & 24 & 2,2 & 1.069 & 44 & 1.009 & 13.463 & $-5,4$ \\
\hline Canarias & 82 & 4,9 & 2.739 & 33 & 1.636 & 10.340 & 39,2 \\
\hline Castilla-La Mancha & 71 & 4,3 & 1.926 & 27 & 1.166 & 2.116 & $-0,3$ \\
\hline Andalucía & 204 & 2,9 & 12.223 & 60 & 1.736 & 8.190 & 27,0 \\
\hline Extremadura & 76 & 7,2 & 763 & 10 & 722 & 2.064 & 1,1 \\
\hline Total $^{\text {(b) }}$ & 826 & - 2,3 & 45.478 & 55 & 1.239 & 8.946 & $10,8 \%$ \\
\hline
\end{tabular}

Fuentes: Ministerio de Trabajo y Asuntos Sociales, Memoria anual 1994, previsiones 1995. Plan Concentado de Prestaciones Básicas en Corporaciones (Madrid: Ministerio de Trabajo y Asuntos Sociales, 1996), p. 6.

Notas: (a) Los datos del crédito asignado para las prestaciones por persona atendida se refieren al año 1995

(b) No incluye la Comunidad Foral de Navarra, el Pais Vasco, Ceuta y Melilla.

Se produce así un incremento en la media de número de proyectos por cien mil habitantes, que se sitúa en 2,3 proyectós. Sin embargo, el incremento se produce de forma desigual entre las quince Comunidades Autónomas. Mientras que la Comunidad Valenciana crece un $52 \%$ en el crédito asignado, Galicia decrece casi un $10 \%$. En ese año siguen creciendo Comunidades ricas en renta per capita para seguir decreciendo en Comunidades con menor renta per capita. Las Islas Baleares incrementa su crédito por habitante en un $6 \%$ mientras que Extremadura sólo crece un $1 \%$ (sólo recibe cada habitante al año 8 mil pesetas de media más que el año anterior).

La tabla muestra que la dispersión de recursos entre las Comunidades Autónomas reproduce desigualdades reales, así como problemas en la organización, sobre todo si se miden esas desigualdades con el coste que se destina a cada persona atendida del total de dinero disponible para el desarrollo de servicios sociales. Las dos Comunidades Autónomas que más dinero destinan por persona atendida son Comunidades ricas y descentralizadas. Sorprende que una persona atendida en esas Comunidades reciba una media de recursos mayor que el resto de Comunidades del sistema. La distribución es inversamente proporcional a la riqueza de las regiones. Además, el presupuesto se mide por personas atendidas. Una persona atendida en Extremadura recibe 2.064 pesetas por caso mientras que una persona atendida en la Comunidad de Madrid o en Islas Baleares recibe una media de 28 y 36 mil pesetas, respectivamente. El dato sugiere la existencia de una doble velocidad en la red de protección social primaria. Esta evidencia empírica explica la dispersión en los indicadores previamente observados. Se abre así un interrogante sobre los motivos por los que dos personas atendidas por una misma red de atención social y a las que se le ofrece una misma prestación social, en una Comunidad la atención equivale a 10 veces más recursos en pesetas para ese tipo de atención. El análisis requiere una reflexión de cómo se realiza ese proceso de transición hacia un mayor protagonismo de las Corporaciones Locales que según parece favorece a aquellas Comunidades Autónomas que más 
renta per capita disponen. El análisis de correlaciones muestra las tendencias que ya se observan el año anterior, y se acentúan en 1994. Las Comunidades Autónomas que tienen más proyectos en funcionamiento reciben en 1994 más crédito asignado. Sin embargo, la correlación es negativa cuando la relación lineal se establece entre el número de proyectos y el crédito por cada proyecto. Se acentúa de igual modo la relación estadística lineal negativa al correlacionar el número de proyectos por cien mil habitantes y el crédito por proyecto. El dato más significativo muestra cómo el sistema tiende a la concentración de recursos en torno a los centros y proyectos más desarrollados. La dinámica del reparto del presupuesto es que las Corporaciones Locales cada vez disponen de más recursos, pero sorprendentemente parecen concentrarse en pocas unidades o en aquellas Comunidades en las que se desarrollan pocos proyectos.

En la Tabla 1.8 se analizan los seis indicadores de distribución de recursos en 1994, y se incluye la media de dinero que recibe cada persona atendida respecto de 1995 . Se observa que el sistema presenta un coeficiente de variación de 0,73 en la media de crédito asignado por proyecto. Es el indicador que mayor dispersión presenta, es decir, algunas de las Comunidades Autónomas reciben mucho más dinero respecto de la media en comparación con las que reciben menos dinero por proyecto. Los indicadores utilizados presentan una dispersión media de un $60 \%$ respecto de la media de las quince Comunidades. Es especialmente significativa la dispersión del crédito asignado por persona y año, y el crédito por persona atendida del total de dinero para prestaciones en ese año. El sistema presenta una distribución poco transparente tanto en el análisis de la equidad vertical que considera la distribución de recursos entre las Comunidades Autónomas en función de la renta per capita, como en una falta de equidad horizontal. Las personas atendidas en Comunidades diferentes presentan un coeficiente de variación acotado de un $60 \%$. Los mismos problemas sociales son tratados con diferencia de recursos en unas Comunidades respecto a otras. La Tabla 1.9 compara los coeficientes de variación de los dos años. Se observa que se mantiene estable la dispersión de los indicadores estudiados tras un año. La medición de la dispersión en intervalos de varios años puede ayudar a esclarecer si los recursos se distribuyen de forma más desigual o más equitativa.

Table 1.8

Desigualdad en los indicadores sobre recursos

\begin{tabular}{|c|c|c|c|c|c|c|c|}
\hline Indicadores de recursos & $\mathbf{N}$ & Media & $\begin{array}{l}\text { Desviación } \\
\text { tipica }\end{array}$ & Varianza & Min & Max & $\begin{array}{l}\text { Coeficiente } \\
\text { de variación } \\
\text { acotada }^{\text {(a) }}\end{array}$ \\
\hline Número de proyectos & 826 & 55 & 51,2 & 2.620 & 2 & 204 & 0,58 \\
\hline Crédito total asignado en 1993 (en millones de pta.) & 45.479 & 3.032 & 3.113 & 9.689 .088 & 300 & 12.223 & 0,62 \\
\hline Media de crédito por proyecto (en miles de pta.) & - & 83 & 63,04 & 4.629 & 10 & 203 & 0,73 \\
\hline Coste pana prestaciones/persona atendida (en pta.) & 一 & 12.885 & 10.233 & 10.472 & 2.064 & 36.556 & 0,61 \\
\hline Crédito asignado por habitante(año (en pta.) & - & 1.209 & 367 & 135.030 & 598 & 1.792 & 0,64 \\
\hline
\end{tabular}

Notas: (a) El coeficiente de variación acotado es igual a la raíz cuadrada del coeficiente entre la desviación típica y la variación máxima que se halla aplicando la fórmula

$\operatorname{Var}_{\max }=\left(\overline{\mathrm{X}} \cdot \mathrm{X}_{\min }\right)^{\prime}\left(\mathrm{X}_{\max } \overline{\mathrm{X}}\right)$. Véase Escobar, Modesto, .Desviación, desigualdad, polarización: Medidas de la diversidad social., Revista de Investigaciones Sociológicas 82 (1998), pp. 9-36.

\section{Eficacia, eficiencia, efectividad}

La eficiencia analiza el esfuerzo de los recursos invertidos para que los objetivos programados se cumplan. Analiza el equilibrio entre el coste y la efectividad a través del impacto del sistema público con énfasis en la equidad entre las Comunidades Autónomas y los estilos de gestión que realizan cada gobierno y administración. Se trata pues de estudiar la utilidad de las actuaciones, que en el caso del Plan Concertado se mediría por el número de personas integradas en la sociedad a través del sistema público de atención primaria y su capacidad de resolución de situaciones de emergencia. Éste es un indicador difícil de obtener. 
La eficacia, eficiencia y efectividad son tres conceptos que no sólo miden el número de personas atendidas, sino que estudian la viabilidad de que todas las personas sean atendidas con niveles de eficiencia similares. El objetivo es garantizar la equidad en sentido vertical y horizontal. Se debe pues analizar el sistema de atención social desde esa vertiente doble. La aportación de las distintas Administraciones a la financiación de los servicios sociales se diferencia según si las Comunidades Autọ́- nomas son del tipo 151 o 143. En la Tabla 1.10 se presenta la aportación relativa a las diversas Administraciones Públicas en las Comunidades Autónomas en el año 1993. Se presentan los totales de crédito en porcentajes y datos absolutos. Los datos de los Gobiernos de las Comunidades Autónomas se refieren al año 1992. El objetivo es comprobar si existe alguna relación entre el tipo de partido político que gobierna en cada Comunidad Autónoma con la distribución de los créditos al año siguiente.

\begin{tabular}{|c|c|c|c|c|c|c|c|c|}
\hline \multicolumn{9}{|c|}{$\begin{array}{l}\text { Trabla } 1.9 \\
\text { Análisis de la dispersión en un año }\end{array}$} \\
\hline \multirow{2}{*}{ Indicadores de recursos } & \multicolumn{4}{|c|}{1993} & \multicolumn{4}{|c|}{1994} \\
\hline & $\mathbf{N}$ & Media & DT & $\mathrm{CVa}$ & $\mathbf{N}$ & Media & DT & $\mathrm{CVa}$ \\
\hline Número de proyectos & 815 & 55 & 51,5 & 0,60 & 826 & 55 & 51,2 & 0,58 \\
\hline Número de proyectos $/ 100.000$ habitantes & - & 2,71 & 2 & 0,63 & - & 2,67 & 2 & 0,64 \\
\hline Crédito total asignado en 1993 (en millones de pta.) & 41.016 & 2.735 & 2.640 & 0,64 & 45.479 & 3.032 & 3.113 & 0,62 \\
\hline Media de crédito por proyecto (en miles de pta.) & - & $\pi$ & 70,7 & 0,73 & - & 83 & 63,04 & 0,73 \\
\hline Crédito asignado por habitante(año (en pta.) & - & 1.122 & 367 & 0,62 & - & 1.209 & 421 & 0,64 \\
\hline Coste para prestaciones/persona atendida (en pta.) & - & - & - & - & - & 12.885 & 10.233 & 0,61 \\
\hline
\end{tabular}

Notas: (a) El coeficiente de variación acotado es igual a la raíz cuadrada del coeficiente entre la desviación úpica y la variación máxima que se halla aplicando la fómula

$\operatorname{Var}_{\max }=\left(\overline{\mathrm{X}}-\mathrm{X}_{\min }\right)^{*}\left(\mathrm{X}_{\max }-\overline{\mathrm{X}}\right)$. Véase Modesto, Escobar .Desviación, desigualdad, polarización: Medidas de la diversidad social, Revista de Inuestigaciones Sociológicas 82 (1998), pp. 936.

El Plan Concertado distribuye los créditos de forma diferente, sin que a priori se observe ningún criterio estrictamente social o referente a las condiciones socioeconómicas coyunturales de cada región. Los totales muestran que la media del crédito aportado por las Corporaciones Locales es la mitad que el crédito aportado por el Ministerio de Trabajo y Asuntos Sociales. Las Comunidades Autónomas junto a las Corporaciones Locales, al contrario, contribuyen con la mitad del crédito asignado. Son las Corporaciones Locales (la administración más cercana a los/as ciudadanos), las que aportan casi la mitad del crédito. Esta tendencia se cumple en todas las Comunidades Autónomas a excepción de Cataluña ${ }^{17}$. Las Corporaciones Locales son las administraciones que mayor crédito se les asigna en la mayor parte de las Comunidades Autónomas, sobre todo si éstas son Comunidades ricas. En el caso de las Islas Baleares y Madrid, las Corporaciones Locales aportan aproximadamente un 70\% del presupuesto anual. Otras Comunidades Autónomas que siguen esta tendencia son el Principado de Asturias y Castilla y León. La distribución es más confusa en las Comunidades de rango medio. La distribución del crédito se presenta aleatoriamente. La Comunidad Valenciana y Cantabria son las dos Comunidades Autónomas en las que las Corporaciones Locales gestionan menos los servicios sociales. El polo opuesto son las Comunidades como Principado de Asturias, Castilla y León o Islas Baleares, en las que las Corporaciones Locales mayor control tienen.

La última columna de la tabla señala además el partido político que gobiema en 1992 en cada Comunidad. El objetivo es comprobar si existe alguna relación entre el tipo de gobierno y las aportaciones en los servicios sociales de las diferentes Administraciones. Los dos casos extremos validan la relación. El Ministerio de Asuntos Sociales sólo aporta un 12\% de los gastos en servicios sociales en las Islas Baleares (con un gobierno del PP); por el contrario, los servicios sociales corren a cargo del Ministerio en un 40\% en Extremadura (gobierno del PSOE). Sin embargo, casos como la Comunidad de Madrid y Aragón contradicen la tendencia. Como se aprecia en el análisis de correlaciones, existe una correlación positiva del 0,35 entre el tipo de gobierno de la Comunidad y el predominio en la gestión de las Corporaciones locales. Se observa que en las tres Comunidades Autónomas en las que en 1993 gobierna el Partido Popular se financian la mayor parte de los servicios sociales desde las Corporaciones Locales. El Ministerio (el gobierno central) se preocupa algo menos de las Comunidades con un gobierno autónomo distinto. A pesar de la relevancia de estos datos hay que entender cada 
Tabla 1.10

Aportación de las Administraciones Públicas según Comunidades Autónomas, crédito para 1993

\begin{tabular}{|c|c|c|c|c|c|c|c|}
\hline \multirow{3}{*}{ Comunidades Autónomas } & \multicolumn{4}{|c|}{ Crédito asignado por parte de } & \multirow{2}{*}{\multicolumn{2}{|c|}{$\begin{array}{c}\text { Total } \\
\text { (en millones pta) }\end{array}$}} & \multirow{3}{*}{$\begin{array}{l}\text { Tipo de } \\
\text { Gobiernc } \\
\text { (en 1992 }\end{array}$} \\
\hline & \multirow{2}{*}{$\begin{array}{l}\text { Ministerio de } \\
\text { Trabajo y Asuntos } \\
\text { Sociales } \\
{ }^{(a)}\end{array}$} & \multirow{2}{*}{$\begin{array}{l}\text { Comunidades } \\
\text { Autónomas }\end{array}$} & \multirow{2}{*}{$\begin{array}{l}\text { Corporaciones } \\
\text { Locales }\end{array}$} & \multirow{2}{*}{$\underset{\text { (b) }}{\text { Remanente }}$} & & & \\
\hline & & & & & $\%$ & $\mathbf{N}$ & \\
\hline Islas Baleares & $12 \%$ & $18 \%$ & $70 \%$ & - & $100 \%$ & 1.334 & $\mathrm{pp}$ \\
\hline Cataluña & 36 & 36 & 28 & - & & 3.761 & $\mathrm{CiU}$ \\
\hline La Rioja & 43 & 44 & 13 & - & & 301 & PSOE \\
\hline Comunidad de Madrid & 15 & 15 & 71 & - & & 7.308 & PSOE \\
\hline Comunidad Valenciana & 33 & 46 & 22 & - & & 2.593 & PSOE \\
\hline Aragón & 24 & 26 & 50 & - & & 1.254 & PSOE \\
\hline Principado de Asturias & 19 & 20 & 61 & - & & 1.377 & PSOE \\
\hline Cantabria & 41 & 41 & 18 & - & & 317 & PSOE \\
\hline Galicia & 23 & 30 & $1^{42}$ & 4,3 & & 3.046 & PP \\
\hline Castilla y león & 15 & 25 & 60 & - & & 4.342 & $\mathrm{PP}$ \\
\hline Región de Murcia & 22 & 46 & 32 & - & & 1.113 & PSOE \\
\hline Canarias & 18 & 36 & 46 & 0,1 & & 1.966 & PSOE \\
\hline Castilla-La Mancha & 23 & 37 & 41 & - & & 1.932 & PSOE \\
\hline Andalucia & 17 & 25 & 49 & 8,5 & . & 9.618 & PSOE \\
\hline Extremadura & 40 & 41 & 19 & - & & 754 & PSOE \\
\hline Total $^{(b)}$ & $21 \%$ & $28 \%$ & $49 \%$ & $2,3 \%$ & $100 \%$ & 41.016 & PSOE \\
\hline
\end{tabular}

Fuentes: Ministerio de Asuntos Sociales, Memoria anual 1993, previsiones 1994. Plan Concentado de Prestaciones Básicas en Corporaciones (Madrid: Ministerio de Trabajo y Asuntos Sociales, 1995), p. 18.

Notas: (a) Antes de 1996 es el Ministerio de Asuntos Sociales.

(b) Dinero que sobra del coste.

(c) No incluye la Comunidad Foral de Navarra, el País Vasco, Ceuta y Melilla.

Comunidad Autónoma como una realidad social diferenciada en la que se pueden considerar factores políticos y económicos diferentes. Además, existe una correlación negativa - 0,47 entre el crédito total asignado para 1993 y las aportaciones del Ministerio de Trabajo y Asuntos Sociales.

El análisis de la Memoria anual de 1994 y 1995 sobre el Plan Concertado permite establecer algunas hipótesis provisionales de una realidad compleja, que permite analizar la estructura social española. Sería importante conocer en profundidad las necesidades de la población en servicios sociales, es decir, la demanda y no tanto la oferta. Se confirma en la Tabla 1.11 la tendencia a un protagonismo mayor de las Corporaciones Locales al año siguiente en la provisión de servicios. En 1994 las Corporaciones Locales sostienen ya el coste del sistema en un $50 \%$. Las Comunidades Autónomas lo hacen en un 30\%, y el Ministerio de Asuntos Sociales en un $20 \%{ }^{18}$. Pero no en todas las Comunidades Autónomas se produce una descentralización en el coste de la red básica. Es una descentralización gradual pero heterogénea sin que se observen criterios claros en el reparto de los costes ${ }^{19}$. La variable tipo de Gobierno. tampoco permite comprender los criterios (si es que existen) en el reparto de recursos. En Islas Baleares y Castilla y León, ambas con gobiernos del PP, se incrementa el protagonismo de las Corporaciones Locales. Pero en Cantabria la tendencia es a la inversa. La diferencia más notable radica en que Extremadura, que es una Comunidad tradicionalmente socialista, no se beneficia de una proporción mayor de crédito asignado: Por el contrario, Islas Baleares - región gobernada por el Partido Popular- recibe una proporción aún mayor del crédito asignado en servicios sociales. Conviene analizar por separado cada proceso de descentralización autonómica, pues cuando el proceso de transferencias de competencias a las Comunidades Autónomas y las Corporaciones Locales es más reciente el desarrollo de los servicios sociales suele ser menor. 


\section{Tabla 1.1.1}

\section{Aportación de las Administraciones Públicas según Comunidades Autónomas, crédito para 1994}

\begin{tabular}{|c|c|c|c|c|c|c|c|}
\hline \multirow{3}{*}{ Comunidades Autónomas } & \multicolumn{4}{|c|}{ Crédito asignado por parte de } & \multirow{2}{*}{\multicolumn{2}{|c|}{$\begin{array}{c}\text { Total } \\
\text { (en millones pta) }\end{array}$}} & \multirow{3}{*}{$\begin{array}{l}\text { Tipo de } \\
\text { Gobierno } \\
\text { (en 1992) }\end{array}$} \\
\hline & \multirow{2}{*}{$\begin{array}{l}\text { Ministerio de } \\
\text { Trabajo y Asuntos } \\
\text { Sociales }{ }^{(a)}\end{array}$} & \multirow{2}{*}{$\begin{array}{l}\text { Comunidades } \\
\text { Autónomas }\end{array}$} & \multirow{2}{*}{$\begin{array}{l}\text { Corporaciones } \\
\text { locales }\end{array}$} & \multirow{2}{*}{$\underset{\text { (b) }}{\text { Remanente }}$} & & & \\
\hline & & & & & $\%$ & $\mathbf{N}$ & \\
\hline Islas Baleares & $11 \%$ & $12 \%$ & $76 \%$ & - & $100 \%$ & 1.421 & PP \\
\hline Cataluña & 23 & 40 & 23 & - & & 3.719 & $\mathrm{CiU}$ \\
\hline La Rioja & 43 & 43 & 14 & - & & 300 & PSOE \\
\hline Comunidad de Madrid & 16 & 16 & 68 & - & & 6.769 & PSOE \\
\hline Comunidad Valenciana & 22 & 54 & 25 & - & & 3.939 & PSOE \\
\hline Aragón & 21 & 37 & 42 & - & & 1.402 & $\mathrm{PAR}^{(\mathrm{d})}$ \\
\hline Principado de Asturias & 18 & 18 & 63 & - & & 1.421 & PSOE \\
\hline Cantabria & 42 & 42 & 16 & - & & 310 & $\mathrm{PP}$ \\
\hline Galicia & 26 & 29 & 45 & 0,3 & & 2.769 & $\mathrm{PP}$ \\
\hline Castilla y León & 14 . & 25 & 61 & - & & 4.709 & $\mathrm{pp}$ \\
\hline Región de Murcia & 23 & 45 & 33 & - & & 1.069 & PSOE \\
\hline Canarias & 13 & 26 & 44 & 17 & & 2.739 & PSOE \\
\hline Castilla-La Mancha & 23 & 35 & 42 & - & & 1.926 & PSOE \\
\hline Andalucía & 14 & 26 & 61 & - & & 12.223 & PSOE \\
\hline Extremadura & 39 & 39 & 20 & 2,0 & & 763 & PSOE \\
\hline Total $^{\text {(c) }}$ & $19 \%$ & $29 \%$ & $51 \%$ & $1,0 \%$ & $100 \%$ & 45.478 & PSOE \\
\hline
\end{tabular}

Fuentes: Ministerio de Trabajo y Asuntos Sociales, Memoria anual 1994, previsiones 1995. Plan Concertado de Prestaciones Básicas en Corporaciones (Madrid: Ministerio de Trabajo y Asuntos Sociales, 1996$),$ p. 6.

Notas: (a) Antes de 1996 es el Ministerio de Asuntos Sociales.

(b) Dinero que sobra del coste.

(c) No incluye la Comunidad Foral de Navarra, el País Vasco, Ceuta y Melilla.

Las Comunidades que más dinero reciben en términos absolutos son Madrid, Castilla y León, Galicia y Andalucía. Se destina sólo a estas cuatro Comunidades más del $50 \%$ del crédito del sistema. Pero en la distribución controlada por el crédito por habitante las Islas Baleares es la más beneficiada (que sigue siendo la Comunidad con mayor renta per capita). Es curioso que la Comunidad más rica sea la Comunidad más beneficiada por el Plan Concertado. El crecimiento económico tampoco es garantía de que en esa Comunidad los servicios sociales sean menos necesarios. Como se comprueba con las correlaciones, existe una relación escasa entre el tipo de gobierno (partido político gobernante) con el sistema de financiación. Se observa que las Comunidades Autónomas más descentralizadas están gobernadas por el Partido Popular, es decir, que las más centralizadas están gestionadas por gobiemos socialistas.

Es difícil precisar si la hipótesis de la descentralización supone un protagonismo mayor de los gobiernos conservadores. La
Tabla 1.12 presenta las correlaciones de todos los indicadores utilizados en el artículo. Se observa que existe una correlación negativa entre la población de cada Comunidad con la tasa de proyectos por cada cien mil habitantes. La correlación es negativa del orden de $-0,29$ entre la población censal de 1991 de cada Comunidad Autónoma y los proyectos por cien mil habitantes en 1993; y de -0,25 lo mismo para 1994. Ese factor es doblemente negativo si se tiene en cuenta la correlación negativa entre los proyectos por cien mil habitantes con la renta familiar disponible en cada Comunidad Autónoma.

Las Comunidades Autónomas históricamente beneficiadas por el Plan Concertado parecen reproducir el sistema año tras año. Es difícil que una Comunidad en la que un año recibe bastante proporción de crédito asignado, al año siguiente se vea desfavorecida por el reparto. Es una lógica de incentivos perversos que muestra la importancia de la variable tipo de gobierno y 


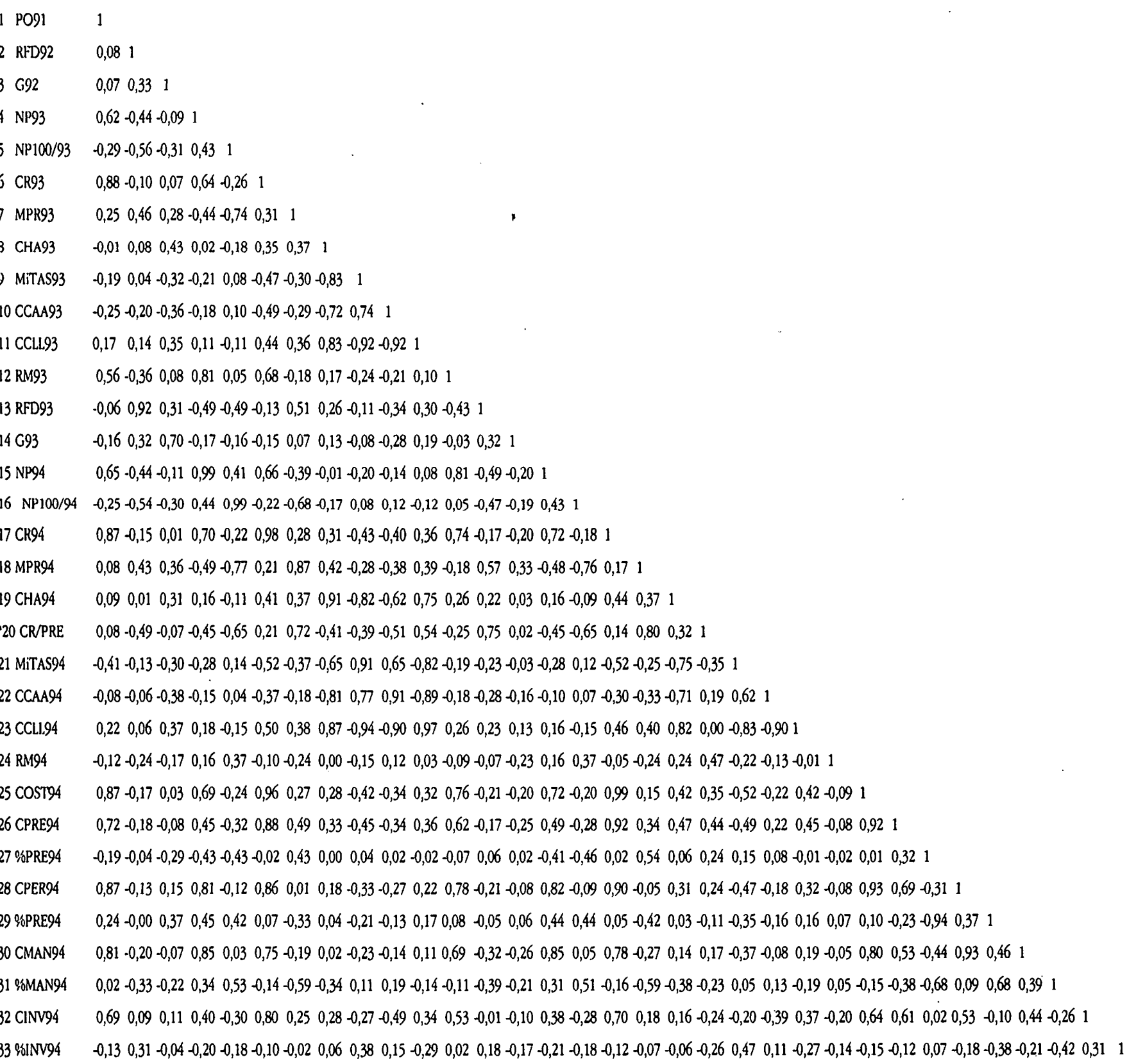

Notas: PO91: Población de hecho (censo de 1991). RFD92: índice de renta familiar disponible por habitante en 1992. G92: Tipo de gobiemo en 1992. NP93: Número de proyectos en 1993. NP100/93: Número de proyectos por 100.000 habitantes en 1993. CR93: Crédito asignado para 1993 (en millones pta.). MRP93: Media de crédito asignado por proyecto (en millones de ptas.). CHA93: Crédito por habitante y año en 1993 (en ptas.). MiTAS93: Crédito asignado por parte del Ministerio de Trabajo y Asuntos Sociales en 1993. CCAA93: Crédito asignado por parte de las Comunidades Autónomas en 1993. CCLL93: Crédito asignado por parte de las Corporaciones Locales en 1993. RM93: Remanentes del crédito de 1993. RFD93: índice de renta familiar disponible por habitante en 1993. G93: Tipo de gobiemo en 1993. NP94: Número de proyectos en 1994. NP100/94: Número de proyectos por 100.000 habitantes en 1994. CR94: Crédito asignado para 1994 (en millones ptas.). MRP94: Media de crédito asignado por proyecto (en millones de ptas.). CHA94: Crédito por habitante y año en 1994. "CR/PRE: Es un indicador que se refiere al coste de las personas atendidas respecto del total de presupuesto para prestaciones en 1995. MiTAS94: Crédito asignado por parte del Ministerio de Trabajo y Asuntos Sociales en 1994. CCAA93: Crédito asignado por parte de las Comunidades Autónomas en 1994. CCLL93: Crédito asignado por parte de las Corporaciones Locales en 1994. RM94: Remanentes en 1994. CPRES94: Coste de las partidas de prestaciones en 1994. \%PRE94: Porcentaje de coste en prestaciones respecto del coste total en 1994. CMAN94: Coste total en mantenimiento en 1994. \%MMAN94: Porcentaje del coste en mantenimiento respecto del total en 1994. CIN94: Coste en inversiones en 1994. \%INV94: Porcentaje de coste en inversiones respecto del total en 1994. 
las negociaciones políticas entre las Comunidades concertantes. La media de crédito por habitante y año correlaciona positivamente $(0,44)$ con el tipo de gobierno de cada Comunidad Autónoma. La pauta muestra que la descentralización de las competencias correlaciona positivamente con gobiernos de partidos más conservadores $(0,33)$. Contribuyen a los servicios sociales con una media de crédito por habitante y año mayor que en las Comunidades Autónomas menos descentralizadas con gobiernos más progresistas.

Los servicios sociales de final de siglo XX se conceptualizan a partir de la proporción de personas que atienden y el tipo de servicios que ofrecen. Pero el rendimiento real se explica mejor según el tipo de Administración que gestiona los recursos. La organización apuesta fuerte por la capacidad de las Administraciones de resolver problemas a partir de la atención social. Sin embargo, ese proceso de asistencialización es un reconocimiento implícito del carácter reactivo de los servicios sociales propuestos por el sector público, así como de su imposibilidad para la creación de condiciones socioeconómicas adecuadas para el total de la población. El decremento de los servicios realizados correlaciona positivamente con una implicación mayor en la gestión de las Corporaciones Locales. La descentralización supone así una interpretación doble. Se observa la pauta clara que una descentralización de los costes mayor conlleva un número menor de personas atendidas. La descentralización se relaciona con el decremento en número de atenciones, trabajador por persona atendida y recursos por centro. La descentralización conlleva que los costes se incrementan pero que se produzcan mejoras en la estructura y funcionamiento de la red de atención.

El protagonismo mayor de las Corporaciones Locales tiene implicaciones reales en la efectividad e impacto menor del sistema debido posiblemente a la mala gestión de los Ayuntamientos o los posibles casos de comupción de una organización excesivamente burocratizada. Otra explicación posible sobre el encarecimiento de la red tiene que ver con la tecnificación, institucionalización y profesionalización de la asistencia. La red pública no atiende a menos población por persona que trabaja en la red, pero el servicio que se ofrece es mejor y más profesional. Se explicaría así que cada trabajador/a atendiese a menos personas debido a que cada servicio requiere más tiempo. Es posible que ambas hipótesis sean ciertas dependiendo de cada región, ayuntamiento o centro de servicios sociales. Pero la conclusión es que la descentralización crea servicios sociales diferenciados según regiones. Esa balcanización de la red pública merece un análisis más en'detalle para cada región, ofreciendo respuesta a los interrogantes sobre la relación cantidad y calidad, así como a la efectividad global del sistema ante situaciones de emergencia y problemas sociales. El objetivo es responder a si esa transformación estructural e institucional repercute en una adecuación mejor de los centros, personal y funcionamiento del sistema al contexto social de cada región y en consonancia con cada problemática social. Es importante un análisis más detallado de ese proceso subsidiario de descentralización vertical.

El Plan Concertado es el resultado de un cierto vacío institucional en sistemas de protección social heredado del franquismo. Pero es también el resultado de una reforma en la concepción y distribución de competencias entre las unidades administrativas diferentes. El rendimiento del Plan Concertado es de difícil comparación en términos de eficacia, eficiencia y efectividad con otros programas en políticas de servicios sociales que se desarrollaron en el pasado. No existen experiencias de otros programas de atención social en España con los que contrastar el rendimiento real del sistema de servicios sociales actual y, sobre todo, no hay datos fiables. Previa institucionalización del Plan Concertado no existe una red de servicios sociales públicos compuesta por los tres niveles administrativos del Estado. La eficacia, eficiencia y efectividad dependen de cómo se realice ese proceso de descentralización de competencias, lo que se convierte en la variable dependiente de este análisis.

El éxito o fracaso de la atención social va unido al proceso de descentralización autonómico y local, y a la capacidad de control que se realice sobre el gasto del sistema. La capacidad de control, es decir, la vigilancia entre Administraciones y los mecanismos que garanticen el control y la responsabilidad política explican el éxito o el fracaso del impacto de una política pública. La concesión de competencias a las Corporaciones Locales es un factor clave que se acentúa desde el inicio del sistema. Supone un intento de modernizar la atención social desde las Administraciones más cercanas a la población. Pero es también un proceso de hiperorganización en el que aparecen fenómenos que se consideran perversos como el exceso de burocracia, y sobre todo un aumento del coste.

La descoordinación en el proceso de descentralización y distribución de recursos explica el descontrol en los costes. La descentralización se realiza de forma progresiva. El hecho de que las Comunidades Autónomas adquieran las competencias de forma gradual provoca que el impacto del sistema sea distinto (e incluso opuesto) entre unas Comunidades Autónomas y otras. La tesis principal es que el sistema es sobre todo un mosaico de instituciones que funcionan con cierta irracionalidad, en que la oferta de servicios no se adecua a la demanda de cada contexto autonómico. Se demuestra con el análisis su potencialidad a la hora de cubrir los municipios y la población de las regiones, y sus limitaciones en garantizar niveles de eficiencia estandarizados en todos las Comunidades Autónomas. La preferencia en cubrir las zonas urbanas frente a las rurales explica que los servicios sociales está más desarrollados en territo- 
rios en los que la población está más concentrada en las ciudades. Los datos demuestran que se cubre más población que municipios; 0 , lo que es lo mismo, que una parte pequeña de la población no recibe todavía atención social. Se explica así por qué el sistema no cubre a los municipios más pequeños. Las variables que explican el impacto del sistema en los municipios y la población son la dispersión de la población y tasa de urbanización.

El Plan Concertado presenta dos casos anómalos: Comunidad Valenciana y Castilla-La Mancha, que constituyen la evidencia de que el supuesto proceso de balcanización explica no tanto unos servicios sociales con definiciones diferentes sobre la atención social, sino estilos de gestión y administración particulares de cada región. La balcanización del sistema, es decir, las diferencias acentuadas en preferencias del gasto, en niveles de eficacia, eficiencia, así como en la efectividad del sistema se deben al estilo de "hacer política", principalmente a la tendencia del gobierno político de la Comunidad Autónoma. El desarrollo de servicios sociales eficientes depende de la voluntad política de desarrollar campañas de atención social a través del marco del Plan Concertado. Es, pues, importante el estudio de cada uno de los procesos de descentralización junto al grado de implicación de las políticas en desarrollar los diferentes servicios y programas definidos en el marco del Plan Concertado de Prestaciones Básicas. Las Comunidades Autónomas que llevan más tiempo aplicando reformas en la atención y adquiriendo competencias es posible que presenten niveles de eficiencia y preparación mayor que las que han desarrollado su capacidad de gestión autonómica más recientemente.

En todas las Comunidades Autónomas se crean o asimilan, ya desde los años iniciales de la red, aquellos centros más desarrollados y en los que se realiza más atención. El Plan Concertado es sobre todo un intento por modernizar y coordinar la atención de la población más necesitada. La imagen es la de una competencia entre diferentes Administraciones por contribuir en la gestión, pero al mismo tiempo por decidir más sobre su propio modelo de atención. El Plan Concertado se define a partir de centros, personas y servicios homólogos en todas las Comunidades Autónomas. Todas ellas establecen una estrategia que favorece la institucionalización de los centros más modernos descartando a los Albergues y Centros de Acogida que tienen globalmente poco peso en el sistema. La puesta en marcha del sistema conlleva la modernización de la concepción asistencialista, pero sufren un relativo descontrol en su rendimiento. Se invierten recursos diferenciados en cada Comunidad Autónoma pero la tendencia global es a potenciar los centros más modernos que ofrecen más servicios. Es importante tener en cuenta las consecuencias de esa marginalidad referente a los Centros de Acogida y Albengues que suponen pocos centros de esos dos tipos repartidos en las quince Comunidades Autónomas.

Un análisis de los costes del sistema puede ofrecer algunas respuestas sobre los objetivos formales del sistema. Desde el año inicial, la partida del presupuesto que más tiende a aumentar son las prestaciones debido a que el objetivo explícito del sistema es ofrecer mejores servicios de atención social. Tras unos años iniciales en los que la inversión tiende a potenciar la profesionalización del personal, esa tendencia cambia a favor de las prestaciones que parece ser la partida clave para comprender la efectividad y eficacia de los objetivos del sistema. En su conjunto, el sistema mantiene cuatro partidas en inversión del presupuesto con dos pautas diferentes: favorecer las prestaciones y al personal por encima de las inversiones y el mantenimiento. Se explica, así, la mayor concentración de servicios sociales nuevos en centros más complejos que suponen más recursos a la Administración. Realmente cada vez se gasta más en el personal del sistema, y relativamente menos en la atención directa. La red se burocratiza y profesionaliza. Termina siendo un "negocio" del propio personal. La complejización (además de la institucionalización y la profesionalización) explica también que en pocos años el sistema que comienza con poco más de cinco mil millones llega a alcanzar cerca de $60 \mathrm{mil}$ millones de pesetas. El aumento exponencial de los costes explica la institucionalización del Plan Concertado como un brazo visible del Estado de Bienestar producto de ese acuerdo entre Administraciones que se consolida a finales de la década de los noventa.

Un análisis más detallado de los costes del sistema en todas las Comunidades Autónomas puede explicar los casos outliers, es decir, que Comunidades Autónomas que tienen pautas diferenciales que no se ajustan a la media. El caso paradigmático de pautas diferenciales en el desarrollo de la atención social es el caso de Cataluña, caracterizado por el protagonismo del sistema de servicios sociales de la Generalitat y una tradición asociacionista y de voluntariado importante. Esa Comunidad Autónoma se ajusta poco a la media, sobre todo en la partida de prestaciones, a la que sólo destina un $5 \%$ del coste total. Es importante controlar factores externos que inciden en las $\mathrm{Co}$ munidades Autónomas del sistema y pueden variar su efectividad. En Cataluña un mayor asociacionismo complementa las deficiencias aparentes del Plan Concertado y ofrece la imagen de un sistema más eficiente.

Los factores endógenos y exógenos afectan a los índices de necesidades y preferencias en el coste por partidas en cada $\mathrm{Co}$ munidad Autónoma. Un comportamiento deficitario en unas partidas puede verse favorecido por iniciativas de tipo privado como por ejemplo el impacto en la atención social de Cáritas y otras ONG. En las Comunidades Autónomas la inversión se centra en las partidas de prestaciones y personal, ratificando la 
tesis de que en el sistema, ya desde su inicio, se marca como objetivo principal el desarrollo sobre todo de los servicios sociales asistencialistas. Este objetivo es propagado por las propias profesiones nuevas del entorno de la atención social. A su vez, el sistema se profesionaliza. Es un círculo vicioso que se retroalimenta, sin controlarse efectivamente.

Existen pues tendencias que favorecen el aumento del coste a la vez que favorecen que unos servicios y centros pierdan protagonismo en el sistema. El rendimiento en su conjunto es menor cada año, pero es posible que se vean afectadas en mayor medida las Comunidades Autónomas con índices de necesidades más altas y con resultados de su negociación por una gestión de los recursos menor. Parece que el sistema contribuye con más recursos a las Comunidades Autónomas aparentemente más ricas, que tienen mayor protagonismo en la gestión de los servicios sociales. Esto parece una contradicción. Se establece una secuencia que favorece a las Comunidades más descentralizadas en sus administraciones locales y que están gobernadas por partidos conservadores. Casos polares, como el de Islas Baleares y Extremadura, ponen en duda la importancia de la variable "negociación política". La variable clave es la propia descentralización entendida como estrategia política. A una $\mathrm{Co}_{-}$ munidad rica, como Islas Baleares, le conviene asumir competencias en servicios sociales desde las Corporaciones Locales, pues así se garantiza un papel central en la gestión de los recursos. La variable fundamental que explica la estructura del sector (público) de servicios sociales es el ser una Comunidad rica y poseer contribuyentes que paguen los servicios sociales que son luego gestionados desde las Corporaciones Locales. Esa lógica es la inversa en las Comunidades Autónomas más pobres, en las que la estrategia asume (algo acertadamente) que un mayor protagonismo de la Administración central le supone mayores recursos en servicios sociales. El análisis correlacional demuestra que la estrategia puesta en práctica por las Comunidades ricas ha favorecido su gestión. Se establece así un interrogante sobre los efectos de un sistema que considera que la descentralización de los recursos y el pacto entre Administraciones es un sistema que garantiza la universalidad y mejora de los servicios sociales. El análisis realizado sobre equidad territorial pone en duda ese principio de redistribución, que fomenta desigualdades en la oferta de servicios sociales, y seguramente no hace variar demasiado la demanda. Roussonianamente el ser humano nace desigual, y el sistema lo hace más desigual todavía. No parece fácil cambiar esa hipótesis ilustrada sin transformar la estructura social española.
- University of Illinois.

- Agradezco las críticas y comentarios de Jordi Caïs, Jesús M. de Miguel, Sonia Frías, Teresa García, Francisco J. Granados, Marga Marí-Klose, Pau Marí-Klose, Raul Tormos, Elisabeth Vaquera y Andrés Walliser. Para más información se puede contactar por correo electrónico a: xescan@eco.ub.es.

1 La distribución de los créditos para las prestaciones básicas de servicios sociales en corporaciones locales mediante convenios-programa se rige por la Ley 41/1994, de 30 de diciembre, de Presupuestos Generales del Estado para 1995 (BOE, n. 313 de 31 de diciembre). Se asigna a las Comunidades Autónomas para ese año la cantidad de 10.513 millones de pesetas a la aplicación presupuestaria 27.03.313L.451.

- La memoria anual del Plan Concertado presenta la distribución del coste a partir de dos clasificaciones: el crédito asignado a cada Comunidad Autónoma comprometidos en los protocolos adicionales suscritos en 1995, un crédito realmente transferido recogiendo la diferencia en las correspondientes addendas que justificarían en 1996.

${ }^{3}$ Véase la discusión sobre el residuo fiscal. como mecanismo basado en transferencias desde el gobierno central a los subcentrales para igualar la contribución realizada y los servicios públicos percibidos de ciudadanos/as que viven en zonas geográficas menos ricas (en DOMfNGUEZ DEL BRí, 1998: 32).

"La consecuencia de una política distributiva centralizada de una descentralizada depende de la valoración entre la ineficacia derivada de una centralización de las actividades al coste de la movilidad motivada por una política redistribuida local, también denominado el efecto del voto con los pies.

' Un ejemplo excelente de un mecanismo de distribución de recursos que fomenta la equidad interterritorial en la aplicación de la fórmula RWAP británica en la asignación de los presupuestos sanitarios. Puede verse en (Ana RiCo, 1998: pp. 553-626).

${ }^{6}$ El sistema no atiende a los municipios muy pequeños. Los criterios establecen que la población debe ser del 90\%, la dispersión del 1,5\%, las grandes urbes del 0,7\%, la población dependiente del 2,3\%, la superficie del 5\%, y la insularidad del 5\%. Se ob- tiene un índice resultante que se modifica con la pobreza relativa multiplicado por 33,54 (MiTAS 1994: 4).

En la práctica este criterio se incumple en cinco Comunidades Autónomas del Plan Concertado (Comunidad de Madrid, Cataluña, Cantabria, Región de Murcia y Galicia). Las Comunidades de Castilla-La Mancha y La Rioja perciben el mismo crédito. El resto perciben más crédito que el año anterior, siendo la Comunidad Valenciana la que presenta un crecimiento mayor (52\% seguida de Canarias y Andalucía con un $39 \%$ y $27 \%$, respectivamente).

${ }^{8}$ Es necesario diferenciar entre la equidad de proceso y la equidad de resultados. La equidad de proceso hace referencia a las estrategias de los/as actores que intervienen en el reparto de los recursos entre las unidades administrativas que forman el Estado. La equidad de resultados supone la mirada a posteriori de la efectividad y rendimiento de los recursos. Para comprender la equidad de resultados es necesario evaluar cómo se ha efectuado la descentralización entre las Comunidades Autónomas. Se requiere un estudio de los criterios objetivos de necesidad, los criterios de negociación política entre Administraciones y los mecanismos de participación ciudadana en la toma de decisiones para comprender los resultados de las políticas públicas.

${ }^{9}$ No se consideran los remanentes (el presupuesto sobrante del año anterior) pero son pequeños.

"La productividad en este caso se entiende como la tasa de población atendida. Al inicio del sistema se atiende aproximadamente el mismo porcentaje que en 1994. La productividad es estable. En relación con los costes totales se puede considerar como baja.

"En el reparto de los costes el caso de Cataluña es paradigmático pues ofrece una tendencia contraria al Plan Concertado.

12. Para un análisis en detalle del concepto de desigualdad puede verse el arículo de Modesto Escobar Revista Española de Investigaciones Sociologicas, REIS, número 82 (1998): 9-36 
1" El análisis de todas las variables se realiza en la Tabla 1.12

"Los indicadores de necesidad en servicios sociales se definen a partir de las problemáticas sociales que mayor impacto social tienen sobre grupos de personas en situaciones de emergencia. Otros indicadores más objetivos son los niveles de desempleo, personas con pensiones no contributivas, etc.

"En el proceso de descentralización de competencias a las Comunidades Autónomas se debe considerar el grado de autonomía política de las Comunidades Autónomas según el artículo 151 y el 143, asi como los regímenes forales de Navarra y País Vasco.

1". Téricamente ninguna Comunidad Autónoma puede recibir menos financiación respecto a la que obruvo el año anterior. El punto número dos de la Memoria Anual de 1994 señala que todas las Comunidades Autónomas percibirán al menos la misma cuantía del ejercicio anterior. (MiTAS, 1994: 4).

1- En el caso de Cataluña no se asume mucho gasto de servicios sociales básicos (sólo el 28\%), siendo el Ministerio de Trabajo y Asuntos Sociales junto con la Comunidad Autónoma las dos Administraciones que más gastan (en Cataluña) en esas materias. Es un caso similar a La Rioja, Cantabria y Extremadura.

18. No se consideran los remanentes. En 1994 suponen el 1\% del presupuesto total del Plan Concertado.

1) Es una de las constantes que se repite en todas las distribuciones de los costes a nivel de Comunidades Autónomas.

\section{Bibliografia}

AHMAD, Ehtisham, et al., Financing Decentralized Expeditures (Washington DC: Edward Elgar, 1997), $396 \mathrm{pp}$

BRINT, Steven, In the Age of Experts: The Changing Role of Professionals in Politics and Public Life (New Jersey: Princeton University Press, 1994), 274 pp.

Boxx, Carles, Partidos políticas, crecimiento e igualdad: Estrategias económicas conservadoras y socialdemócratas en la economía mundial (Madrid: Alianza, 1996), 407 pp.

CORONa RAmON, Juan, y Pedro PUY FraGa, Federalismo competitivo y financiación autonómica, Jornadas de Economía Pública (Valencia, febrero 1998).

DOMINGUEZ DEL BRí, Francisco, Análisis económico del federalismo fiscal: Una selección de diez trabajos publicados originalmente por el autor, sobre diversos aspectos de la especialidad (Barcelona: Universidad de Barcelona, 1998), 294 pp. Véase especialmente el artículo -El objetivo de la redistribución ante diversos niveles de hacienda en un Estado de las Autonomías y las estrategias cooperativas.

ESCOBAR, Modesto, •Desviación, desigualdad, polarización: Medidas de la diversidad social, Revista de Investigaciones Sociológicas 82 (1998), pp. 9-36.

FERNÁNDEZ GOMEZ, Natividad, La financiación de las Comunidades Autónomas: Una propuesta de corresponsabilidad fiscal (Madrid: Instituto de Estudios Económicos, 1993), $385 \mathrm{pp}$.

Mıcuel, Jesús M. de, Estrictura y cambio social en España (Madrid: Alianza, 1998) $681 \mathrm{pp}$.
Mogín Barquín, M. Teresa. El Plan Concertado de Prestaciones Básicas de Servicios Sociales en las Corporaciones Locales, pp. 123-124 en Ministerio de Asuntos Sociales, Primeras Jornadas Nacionales de Servicios Sociales Comunitarios (Madrid: Ministerio de Asuntos Sociales, 1995), $180 \mathrm{pp}$.

MoTA, Rosalia, :Derechos sociales y pensiones en España, (Madrid: Fundación Argentaria, 1996), pp. 289-319 en Berta ÁlVAREZ-MiRavDA. y otros, Dilemas del Estado de Bienestar (Madrid: Fundación Argentaria, 1996), 439 pp.

PIERSON, Paul, Dismantling the Welfare State? Regan, Thatcher, and the Politics of Retrenchment (Cambridge: Cambridge University Press, 1994), 213 pp.

Putnam, D. Robert, Making Democracy Work (New Jersey: Princeton University Press, 1993), $256 \mathrm{pp}$.

REY DEL CASTILOO, Javier, Descentralización de los servicios sanitarios: Aspectos generales y análisis del caso español (Granada: Escuela Andaluza de Salud Pública, 1998). $445 \mathrm{pp}$.

RICO GOMEZ, Ana, Descentralización y reforma sanitaria en España (1976-1996): Intensidad de preferencias y autonomia política como condiciones para el buen gobiemo (Madrid: Centro de Estudios Avanzados en Ciencias Sociales de la Fundación Juan March, 1998), $730 \mathrm{pp}$.

RodRígueZ CABRERO, Gregorio, LLos servicios sociales en España: implantación, generación de empleo y evaluación de su efectividad, pp. 361-423, en Eduardo Bandrés et al., Las politicas redistributivas (Madrid: Fundación Argentaria, 1996), 426 pp. Es una ponencia del Segundo Simposio sobre Igualdad y Distribución de la Renta y la Riqueza. 
